\title{
DIFFUSE DEGENERATION OF THE CEREBRAL WHITE MATTER IN SEVERE DEMENTIA FOLLOWING HEAD INJURY
}

\author{
BY
}

\author{
SABINA J. STRICH
}

From the Departments of Neurology and Neurological Surgery, Radcliffe Infirmary, Oxford

This paper reports the findings in the brains of five patients who' survived a closed head injury in a more or less decerebrate and extremely demented state, for five to 15 months. These cases were selected from a series of patients who died after prolonged coma or other severe disturbances of consciousness following head injury. Both clinically and pathologically they form a distinct group. The head injuries were uncomplicated, that is, there were no fractures of the skull, no intracranial haematomata or lacerations of the brain, and in particular there was no evidence of raised intracranial pressure at any time, yet the patients remained quadriparetic and almost totally unresponsive from the time of the accident. Pathologically the main finding, and one unsuspected from naked-eye appearances, was a diffuse degeneration of the white matter of the cerebral hemispheres.

Few pathological reports of patients with such a degree of post-traumatic dementia have appeared in the literature, partly due no doubt to the fact that until relatively recently few patients with such severe head injuries survived the acute stage. As far as I know only one of the reported cases, that of Rosenblath in 1899, showed extensive degeneration of the white matter, similar to that in our cases, in a patient who survived a closed head injury in a "sleep-like" state for eight months.

Since the findings in our five cases are so similar, a detailed description of the histology and distribution of the lesions will only be given for Case 1 .

\section{METHODS USED IN THE INVESTIGATION}

The brain and spinal cord were removed in the usual way and fixed by suspension in $10 \%$ formol-saline. In Case 5, the brain was perfused in situ with bismuth carbonate in formol-saline in order to render the blood vessels radio-opaque. Numerous blocks were taken from each brain and spinal cord and embedded in celloidin or paraffin or used for cutting frozen sections. The staining methods employed were haematoxylin and eosin, haematoxylin and van Gieson, Nissl, Mallory's phosphotungstic acid haematoxylin, and Weil's stain for myelin, on all embedded blocks. Glees' or Holmes' silver methods for nerve fibres, the Prussian blue reaction for iron, and the Holzer technique were carried out on many sections. Frozen sections were used for Bielschowsky's silver impregnation and for staining with Sudan IV, Sudan black, and oil red 0 . Much use was made of the Marchi method which was found to give excellent results in these long-standing lesions in spite of very long fixation (nine years in Case 1) in formalin (Smith, Strich, and Sharp, 1956). Since serial sections were not required, a simplified Marchi method was employed: the blocks were washed in tap water for $\mathbf{2 4}$ hours and frozen sections 20 to $40 \mu$ thick were cut and placed into Marchi solution as recommended by Glees (1943). After five to seven days the sections were taken out, washed in tap water for several hours, and mounted in glycerine jelly. With this method there is practically no pseudoMarchi deposit.

TABLE I

CLINICAL DETAILS OF THE CASES

\begin{tabular}{|c|c|c|c|c|c|c|}
\hline \multirow{2}{*}{ Case } & \multirow[b]{2}{*}{$\begin{array}{l}\text { Age in } \\
\text { Years }\end{array}$} & \multirow{2}{*}{$\begin{array}{c}\text { Survival } \\
\text { Time } \\
\text { in Days }\end{array}$} & \multirow[b]{2}{*}{ Injuries } & \multicolumn{3}{|c|}{ Complications } \\
\hline & & & & $\begin{array}{l}\text { Fracture } \\
\text { of Skull }\end{array}$ & $\begin{array}{l}\text { Intracranial } \\
\text { Haematoma }\end{array}$ & Other \\
\hline 1 & 28 & 371 & Laceration $L$. forehead and & None & None & 一 \\
\hline B 2 Female & 32 & 318 & L. Occipital laceration, bleeding & None & Subdural film of & Tracheotomy \\
\hline G.T Male & 41 & 257 & Lacerations vertex and $R$. fore- & None & None & Shock \\
\hline 4 & 27 & 456 & $\begin{array}{l}\text { fibula } \\
\text { Haematoma } R \text {. temple }\end{array}$ & None & None & Tracheotomy \\
\hline $\begin{array}{l}\text { J.M. }{ }^{5} \\
\text { A.T. Female }\end{array}$ & 73 & 142 & $\begin{array}{l}\text { Laceration } R \text {. forehead; fracture } \\
\text { L. femur and clavicle }\end{array}$ & None & & - \\
\hline
\end{tabular}




\section{CASE REPORTS}

The ages and survival periods of the patients and details of the injuries will be found in Table I.

\section{Case 1}

H. B., a man, aged 28 , one year before death was knocked down by a truck and rendered unconscious. Eleven hours later he was still unconscious but responded to painful stimuli by moving all limbs, the left more than the right. Blood pressure, pulse, respirations, and pupillary reactions were normal. There was a laceration on the left forehead, but no skull fractures were seen on radiographs. He lay in the posture which he maintained for the rest of his life, that is, legs strongly extended, the right arm extended at the elbow and internally rotated, and the left arm flexed at the elbow and wrist (cf. Case 2, Fig. 18). He moved all limbs fezbly, the left less than the right, the tendon reflexes were increased on the left, but the spasticity, which was considerable, was more marked on the right. Both plantar responses were extensor. There was a left facial weakness. These signs remained unchanged for the rest of his life, except that the legs became rigid in flexion towards the end. Extensor spasms affecting all limbs and accompanied by profuse sweating were observed during the first three days.

Biparietal burr holes were made on the eighth day. It was found that the brain was not swollen and the intraventricular pressure was normal.

The patient began to yawn, swallow, and shout on the third day and was soon able to take his diet by mouth, though he could rever feed himself. He lay immobile most of the time, becoming restless when disturbed. During the third week he began to open his eyes and a left homonymous hemianopia to menace was demonstrated. The eyes were usually held in conjugate deviation to the right, though he would follow moving objects with them at times. He lay awake most of the day, and though he was very noisy, it is not certain that he ever spoke, and he never obeyed commands. After eight months a slow rhythmic tremor of the right wrist appeared.

The patient eventually became very emaciated and died of bronchopneumonia one year and five days after the accident. He had had no respiratory disturbances or infections throughout his illness, except the terminal bronchopneumonia.

Investigations.-An air encephalogram done four months after the injury showed moderate symmetrical dilatation of the lateral ventricles and some excess of air over the frontal cortex. The cerebrospinal fluid at that time contained $75 \mathrm{mg}$. protein per $100 \mathrm{ml}$. and 4 lymphocytes per c.mm.

The clinical diagnosis was dementia with decerebration due to extensive damage in the hemispheres, especially the right.

\section{Post-mortem Findings in Case 1 (P.M. 511/45)}

Macroscopic.-The patient was very emaciated. Apart from pleural adhesions and bronchopneumonia the significant abnormalities were limited to the central nervous system. There was no evidence of fracture of the skull and the dura was norma There was excess of cerebrospinal fluid in the basal cisterns. The brain and its blood vessels lookef normal except for a little yellowing of the leptof meninges in the left frontal region. The left hemis sphere was cut horizontally, the right coronally There was moderate dilatation of the ventricles including the third; the aqueduct and fourth ventric were normal. A few small areas of yellow pig mentation (old haemorrhages) were scattere of throughout the white matter and basal ganglia $\overrightarrow{\overrightarrow{0}}$ the hemispheres, and two punctate areas of yellow ing were present in the floor of the fourth ventricles There was yellowing of the roof of the left lateran ventricle and a softening in the left side of the corpus callosum.

Microscopic.-The following description of the lesions applies to all five cases.

The most striking finding is a diffuse and ofteg severe degeneration of the white matter throughou the cerebral hemispheres. There is a marked los of nerve fibres in the white matter in which compound granular corpuscles containing lipid are scatteredo sometimes in very large numbers. The degrees of degeneration varies but does not amount to a catis plete destruction of white matter anywhere, çthe remaining nerve fibres and their myelin sheaths being apparently normal (Fig. 1). The cellular reaction apart from compound granular corpuscles, is gre conspicuous and consists of a few plump astrocyes? occasional clumps of glial cells or glial stars, an $\overline{\mathbf{f}}$ के little " round cell" cuffing of the vessels. There little fibrous gliosis and no fibrosis. The oligoderi droglia looks normal. The lipid in the compoun granular corpuscles has the following characteristics it is in the form of colourless, birefringent crysta which stain faintly or not at all with Sudan ID (Fig. 2) and Sudan black. They stain well wit osmic acid (Fig. 3) as used in the Marchi technique and also with oil red 0 . Most of these crystals are clearly intracellular, but long, apparently extra cellular crystals can also be seen.

One rather obvious feature in many paraffin and celloidin sections has been the lobulated spaces bridged by shreds of tissue (Figs. 6, 9, and 20). Thesespaces have never been seen in frozen sections ever. when dehydrated and cleared. They are found is areas in which the white matter is abnormal, bu they do not correspond with collections of fag granule cells. They may, for example, be seen round the edge of a tract, such as the cingulum, whict shows a little degeneration in its centre. These spaces are almost certainly artefacts, but they can be a useful hint to examine carefully the white mattef in which they lie, since they may be present evet 


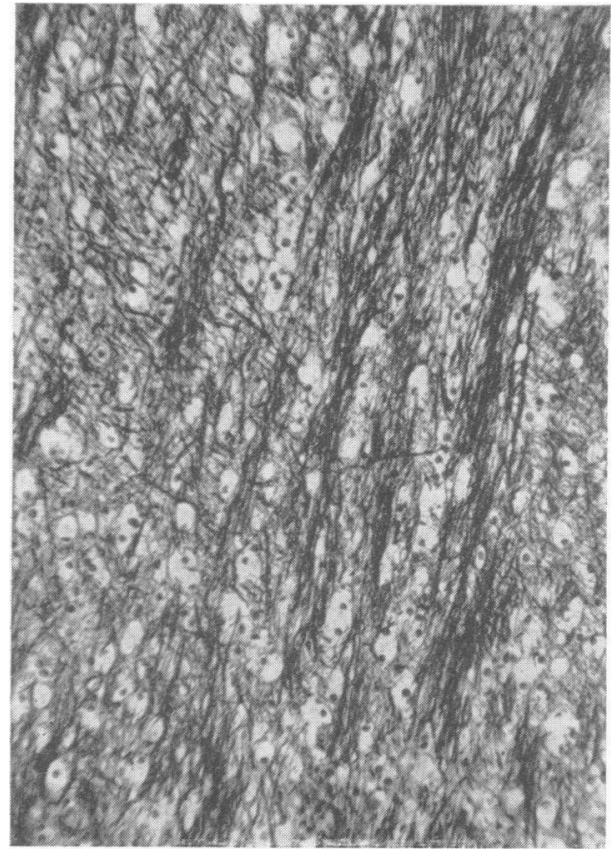

FIG. 1

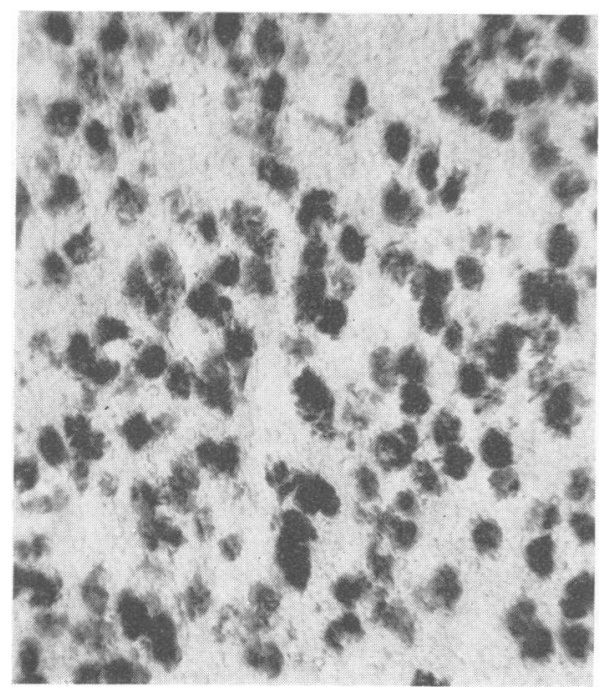

FIG. 3
FIG. 1.-Case 4: White matter from right parietal region showing compound granular corpuscles lying among normal nerve fibres. Glees' silver stain. $\times 190$.

FIG. 2.-Case 4: White matter from right parietal region stained with Sudan IV. Compound granular corpuscles (arrows) can be seen, but their contents are not sudanophilic. $\times 190$.

FIG. 3.-Case 4: White matter from right parietal region, stained by the Marchi technique, showing much lipid. This is contained in compound granular corpuscles. $\times 190$.

FIG. 4.-Case 1: Scar of a small old haemorrhage in the cortex of the insula. Iron-containing macrophages are lying near a blood vessel. Haematoxylin and van Gieson, $\times 62$.

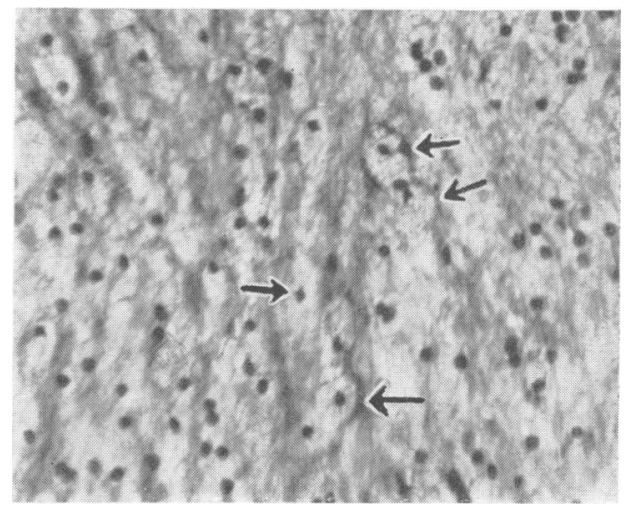

FIG. 2

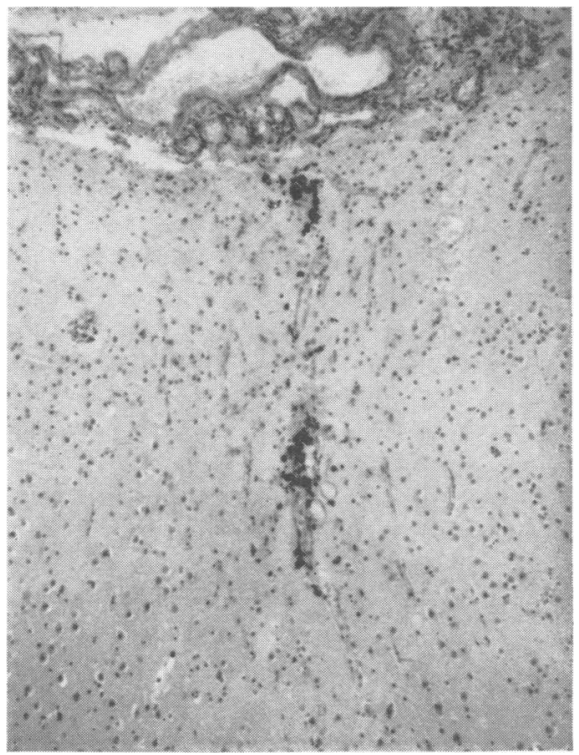

FIG. 4 
when there is only slight degeneration (Figs. 8 and 9).

Some small focal areas of complete destruction of white matter due to old haemorrhages or softenings are also found, the haemorrhages being recognizable by the presence of iron-laden macrophages (Fig. 4). In the focal lesions the contents of the fat granule cells differ from those in the diffuse lesion, in that they stain well with Sudan IV and Sudan black, as well as with osmic acid, and this applies to the small amount of fat seen round blood vessels. All the haemorrhages and some of the softenings show fibrosis and all focal lesions are surrounded by a narrow rim of fibrous gliosis.

Lesions in the cortex are few, though three types may be seen. There are healed traumatic contusions affecting the summits of gyri and the outer layers of the cortex (Figs. 19 and 35), small cortical infarcts situated at the bottom or on the side walls of sulci (Figs. 5, 6, and 31), often affecting the deeper cortical layers only, and occasional small haemorrhages (Fig. 4). In general the cerebral cortex looks remarkably normal. In some areas where the lesion of the underlying white matter is severe, there probably is a slight generalized cell loss, but this is nowhere a striking feature. The nerve fibre degeneration could nowhere be traced into the cortex.

The histology and staining reactions of the diffuse white matter lesion are indistinguishable from those of known Wallerian or secondary degeneration in the same brain. Such secondary degeneration can be seen distal to haemorrhages in the white matter and the corpus callosum or in the descending tracts in the brain-stem and spinal cord.

The easiest way to show the degeneration is by

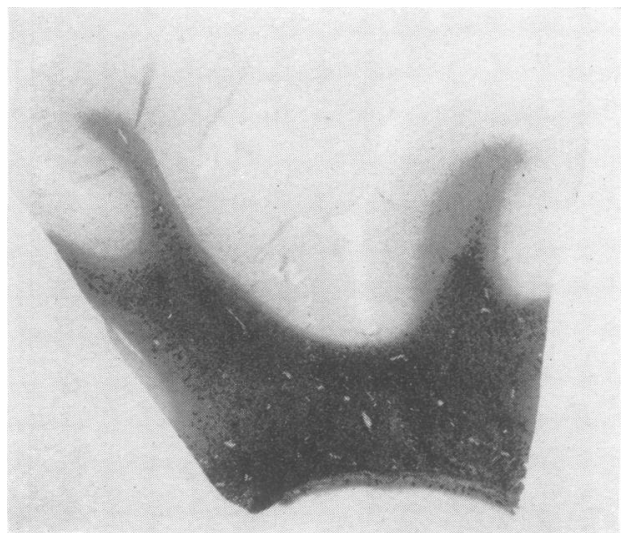

FIG. 5.-Case 1: Right frontal region stained by the Marchi technique. The white matter is full of black-staining products of degeneration. A part of one convolution is spared; notice the sharp line of demarcation between normal and abnormal areas. There is a small cortical softening at the bottom of the sulcus. $\times \mathbf{2 \cdot 2}$.

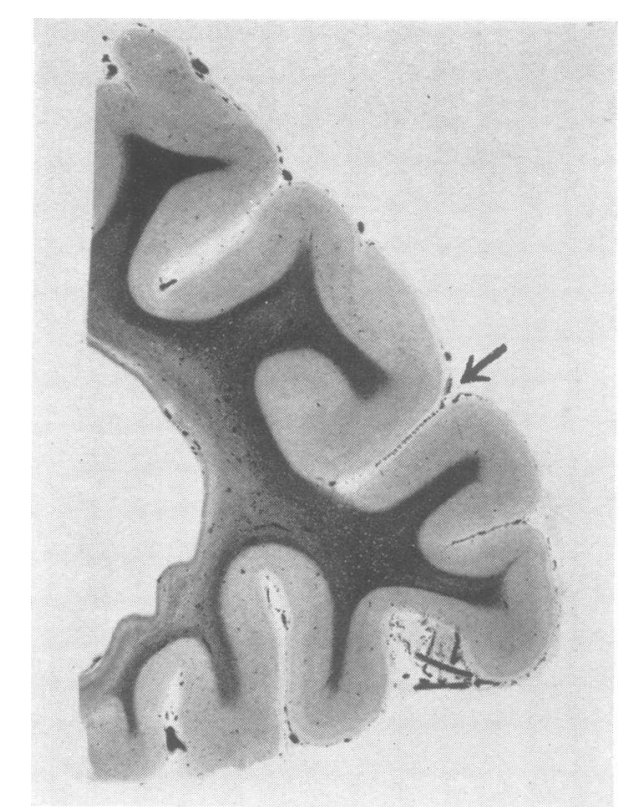

FIG. 6.-Case 1: Right frontal region showing degeneration of the white matter most marked near the ventricle. There is a softening at the bottom of the sulcus marked with an argow The small white spots are not focal lesions but are artefa\&uQ spaces which appear in degenerated white matter (see $2 x t$ ). Weil, $\times 1 \cdot 7$.

the Marchi method, especially in areas where ghe damage is slight or moderate (Figs. 8 and 9). The lesion can, however, be seen with any stain, tho of it may have to be looked for with care.

The blood vessels look normal. Occasionat vessels, especially in Case 4, show an increase io perivascular fibrous tissue.

Distribution of Damaze in Case 1.-There is diffuse degeneration of the white matter affecting af parts of the hemispheres. The cerebral cortex $\overrightarrow{\text { is }}$ normal, apart from slight cell loss in the frontal region where the white matter damage is most severe and a few very small cortical infarcts and haemorrhages (Figs. 5 and 6).

The damage in the two hemispheres is about equath in quantity though not in detail of distribution? It is very severe in the frontal poles superiorly and inferiorly (Figs. 5 and 6), moderate in the posteriog frontal (Figs. 7, 8, and 9) and parietal regions, and slight in the temporal lobes.

In the occipital lobes (Figs. 10 and 11) marke degeneration is present in the internal and extern sagittal strata and there is a little degeneration elser where in the white matter, particularly on the righ?

In view of the bilateral degeneration, which ts only moderate in severity in the region of the motoct 


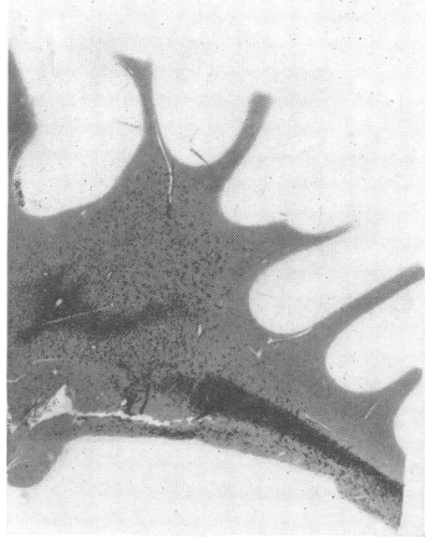

FIG. 7

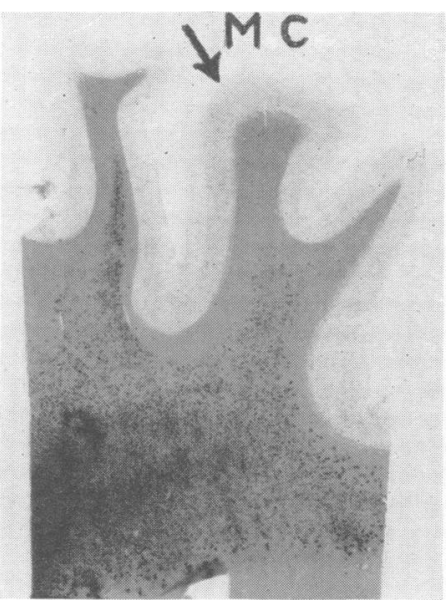

FIG. 8

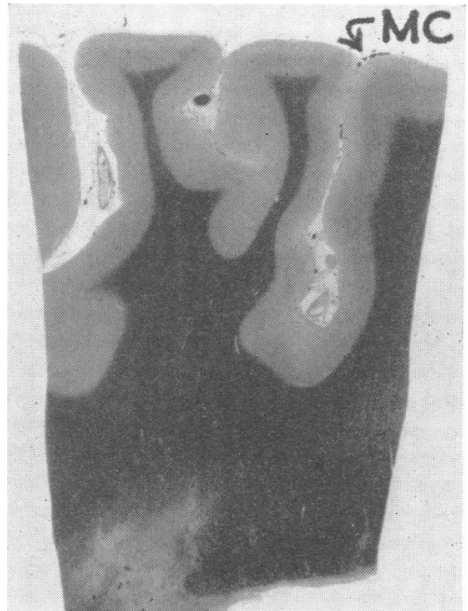

FIG. 9

FIG. 7.-Case 1: Region of right motor cortex (parasagittal section) showing degeneration products in the white matter. Marchi, $\times 1 \cdot 7$.

FIG. 8.-Case 1: Region of left motor cortex (horizontal section) showing degeneration of the white matter. The dense staining at the bottom left-hand corner is due to a softening in the corpus callosum. (MC $=$ motor cortex.) Marchi, $\times 1 \cdot 7$.

Fig. 9.-Case 1: Region of the left motor cortex, block adjacent to that of Fig. 8, stained for myelin. This shows that a diffuse lesion, unless very severe, may be difficult to see with this stain. The completely demyelinated area is a softening in the corpus callosum. The white spots are not focal lesions but are artefacts. $(M C=$ motor cortex.) Weil, $\times 1 \cdot 7$.

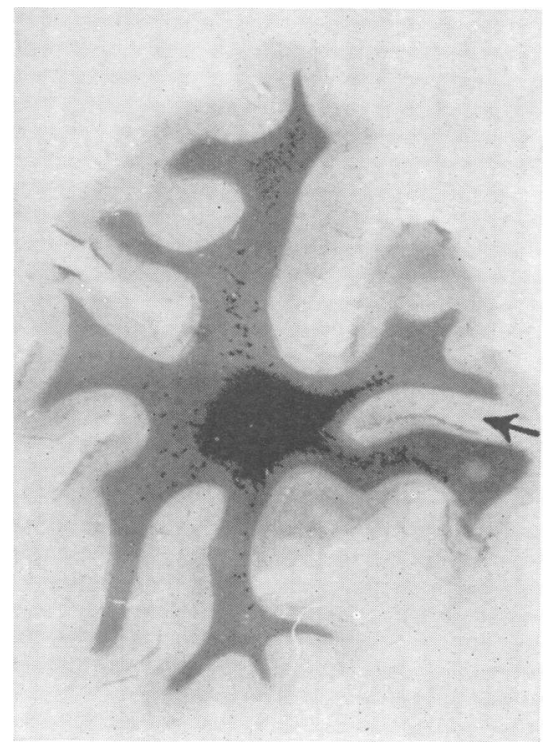

FIG. 10

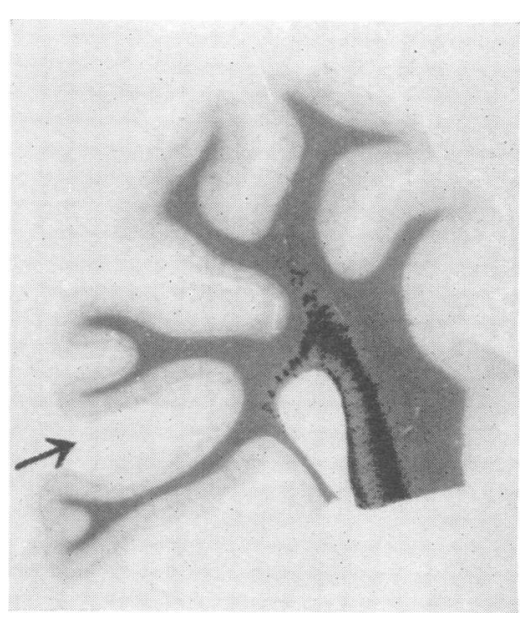

FIG. 11

FIG. 10.-Case 1: Right occipital lobe (coronal section) to show degeneration in the internal and external sagittal strata, and in the white matter including that in the calcarine region (the arrow marks the calcarine fissure). Marchi, $\times 1.7$.

FIG. 11.-Case 1: Left occipital lobe (horizontal section) showing degeneration in the external and internal sagittal strata. There is no degeneration in the calcarine region. (The arrow marks the calcarine fissure.) Marchi, $\times 1 \cdot 7$. 
cortex, it is remarkable that a large number of the fibres which make up the pyramidal tract are interrupted on the right side, whereas almost none are affected on the left, as can be seen in the medulla (Fig. 12). There are no haemorrhages in the internal capsules. Similarly, although the external sagittal stratum is extensively degenerated in both occipital lobes, the fibres of the optic radiation are only affected on the right side, where degeneration can be traced from the lateral geniculate body (Fig. 13) to the calcarine region though not into the visual cortex, which looks normal (Fig. 14). The right lateral geniculate body shows almost complete cell loss, whereas the left is normal (Figs. 15 and 16). Both optic tracts are normal.

Certain peculiarities in the distribution of the white matter degeneration should be noted. In all regions it is particularly well marked near the ventricles (Fig. 6). Occasionally convolutions, or parts of convolutions, look normal, although adjacent parts show marked degeneration, the demarcation between normal and abnormal white matter often being a straight line (Fig. 5). The U-fibres are usually, but not always, spared.

Internal Capsule.-There is severe degeneration in all parts of the right internal capsule, least in the anterior limb. In the left the degeneration is also severe except for the middle portion of the posterior limb which stands out by being almost completely normal.

Thalamus.-This is much shrunken, the different nuclei showing a more or less marked cell loss accompanied by a corresponding degree of gliosis. Numerous compound granular corpuscles are present, particularly in the more heavily myelinated parts. The extent of the damage in the afferent and efferent fibre tracts of the thalamus makes an attempt at exact localization of the degeneration in this nucleus unprofitable, quite apart from the difficulty caused by shrinkage, distortion, and loss of landmarks.

The findings are roughly as follows. On the right there is marked shrinkage of the lateral nucleus and almost complete cell loss in the lateral geniculate body. The anterior and medial nuclei are much better preserved; the centre median nucleus looks normal. On the left the lateral pulvinar, the lateral and the dorsomedial nuclei are severely affected, the medial pulvinar, lateral geniculate body, and centre median nucleus being preserved.

On the whole the nuclei are affected whose efferent or afferent connexions have been interrupted, and it is felt that the thalamic lesions in this and the other cases are secondary to the degeneration of the white matter.
Corpus Striatum.-Except for an occasional smaif haemorrhage this appears normal. The hypothala mus looks normal.

Degeneration is present in the corpus callosuris which has a softening with cyst formation on the left side, in the fornices, in the right mammillo thalamic tract, and in the anterior commissure There are a few fat granule cells in the substantia innominata and in the ansa lenticularis.

Lower Brain-stem.-Degeneration of the des:cending tracts can be followed through the brain-stem into the spinal cord, the corticospinat fibres from the left hemisphere being almos completely spared. The degeneration of the descend $\overline{\bar{p}}$. ing fibres from the right hemisphere is very marke (Figs. 12 and 17) but not complete; some wholo bundles in the pons are unaffected and many normal. fibres can be seen in the pyramid.

There is degeneration in the right medial lemniscus (Fig. 17). This begins in the lower pons where it i

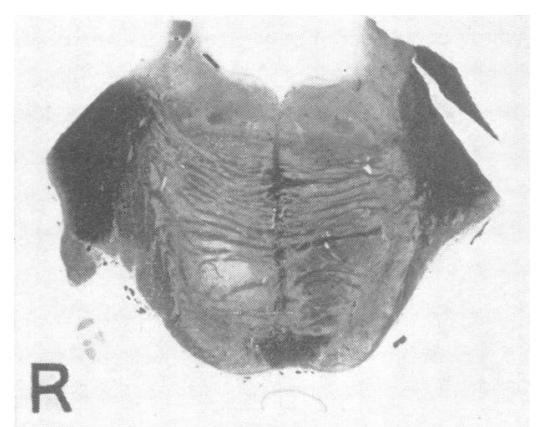

Fig. 17-Case 1: Section through the pons to show degeneratio of the right descending tracts and the right medial lemniscus At a lower level the latter is normal. (cf. Fig. 12.) Weil, $\times 2$

slight, and gradually becomes more marked as it i\& traced up. There is also a little degeneration i $\vec{B}$ both central tegmental tracts. No lesion was found which might have accounted for this or the degeneration of the medial lemniscus. There are. large numbers of fat granule cells and some gliosis. in the left red nucleus; this is due to degeneration it the right superior cerebellar peduncle secondary toa softening. There is some degeneration in the medial longitudinal bundles. There is degeneratioß superficially at the right border of the upper pons over a short distance.

The only abnormalities in the medulla are severe degeneration of the right pyramid and a few fat granule cells in the left (Fig. 12). The nuclei of Goll and Burdach appear normal. The degeneratio in the pyramid can be traced down the spinal cord in the crossed and direct pyramidal tracts. 
FiG. 12
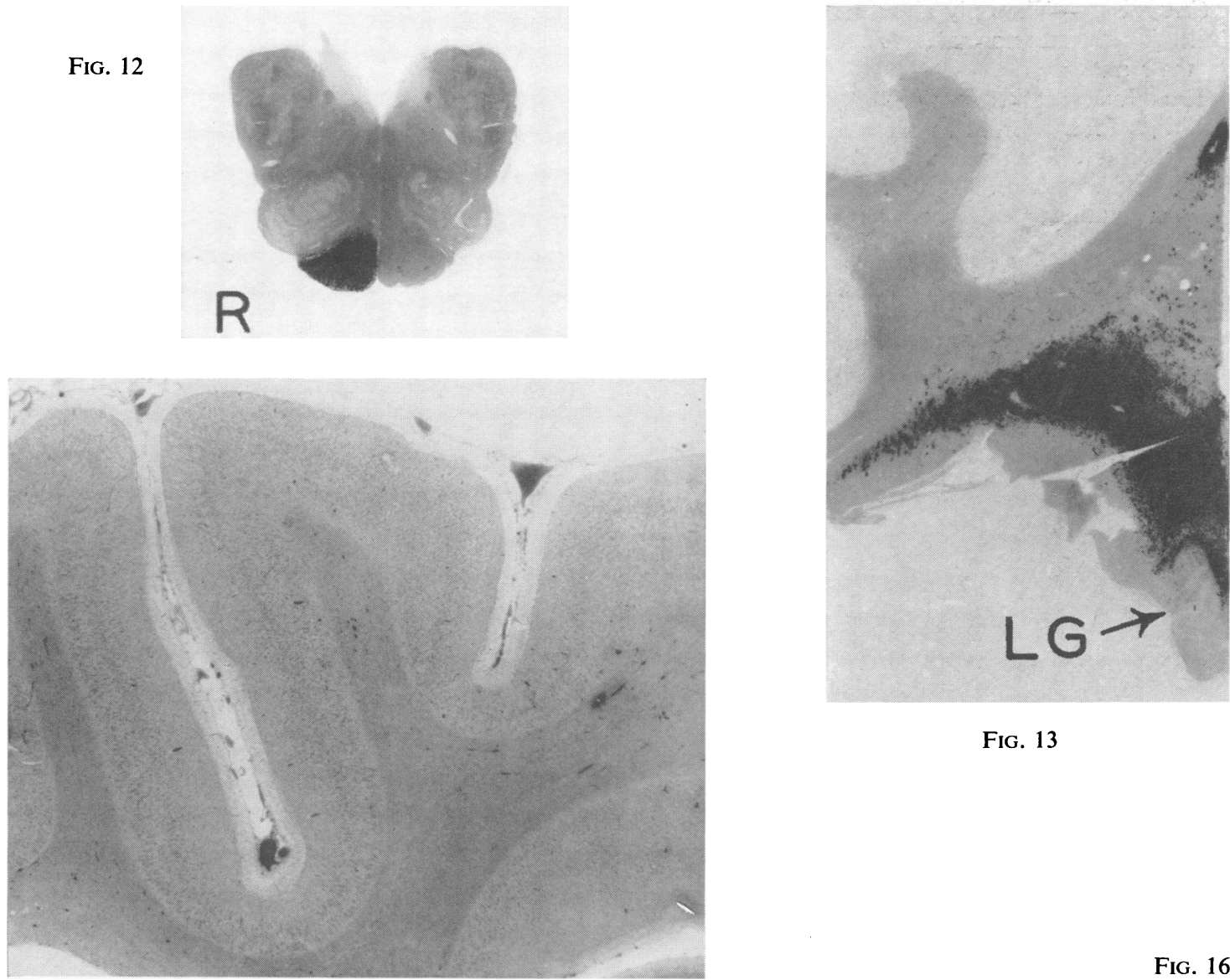

Fig. 13

FIG. 14

FIG. 12.-Case 1: Medulla, showing severe degeneration in the right pyramid. The left contains a few fat granule cells. The rest of the medulla is normal. Marchi, $\times 2 \cdot 4$.

Fig. 13.-Case 1: Coronal section through the right lateral geniculate body (LG) showing the degenerated optic radiation leaving it. Marchi, $\times 2 \cdot 5$.

Fig. 14.-Case 1: Right visual cortex. This looks normal. Nissl, $\times \mathbf{4} \cdot \mathbf{2}$.

FIG. 15.-Case 1: Section through the right lateral geniculate body showing almost complete cell los:. Nissl, $\times 5 \cdot 4$.

FIG. 16. - Case 1: Section through the left lateral geniculate body which is normal. Nissl, $\times 5.4$.

FIG. 15

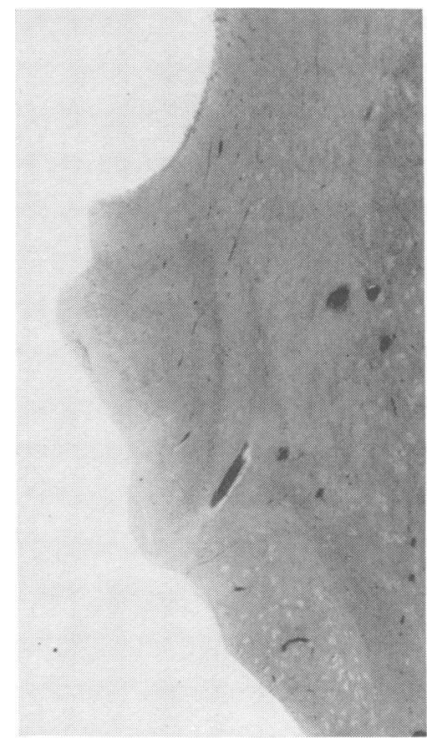

FIG. 16

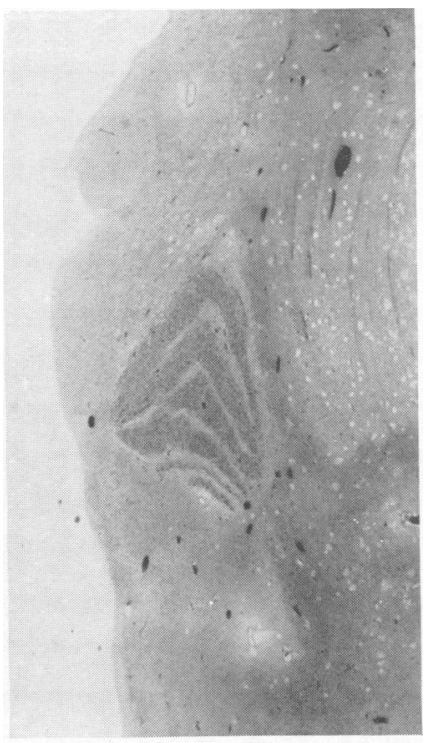


Cerebellum.-The only abnormality is that more Purkinje cells than normal have swellings (torpedoes) on their axons.

The blood vessels in the brain and the leptomeninges look normal in all areas, but there are very recent, evidently terminal haemorrhages near the lateral ventricles. These are the only evidence of recent pathological changes seen in this brain.

\section{Case 2}

B. S., a woman aged 32, a pedestrian, $10 \frac{1}{2}$ months before death was run into by a car and was thrown

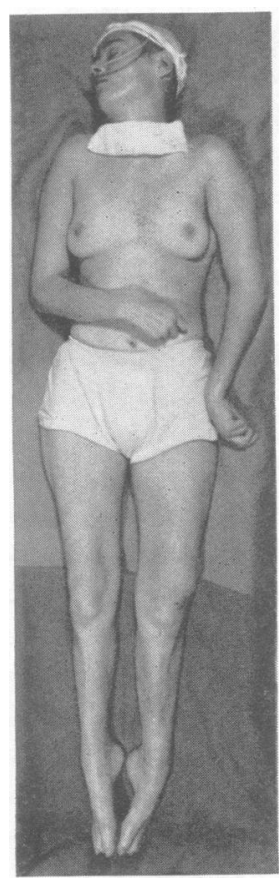

FIG. 18.-Case 2: This shows the characteristic posture of this patient with the left side in the " decerebrate," the right in the " decorticate" attitude. The photograph was taken one month after the accident. to the ground, hitting her head. The accident was witnessed by an experienced nurse, who stated that the patient became unconscious at once and took up the posture shown in Fig. 18 immediately after landing on the ground. She was seen at the Radcliffe Infirmary within 10 minutes of the accident and was then unconscious. Her blood pressure, respiration, and pulse were normal, the pupils were of equal size (after some days the right became slightly larger than the left) and reacted to light, the corneal reflexes were present. There was a laceration in the right occipital region and abrasions on the left temple. The patient was lying in the attitude which remained characteristic for her (Fig. 18), that is, the head was turned to the right, the eyes deviated to the left, the right arm flexed at elbow and wrist, the left extended and hyperpronated, both legs strongly extended, the feet plantarflexed. She was observed to move the right leg and both arms. The slightest stimulation produced so-called " brain-stem attacks" in which the posture described was accentuated, accompanied by hyperpnoea, salivation, and sweating. No skull fractures were seen on radiographs.

Burr-hole exploration was done on the seventh day. There was a thin film of subdural blood over the right hemisphere, but no evidence of a space-occupying clot, and the ventricular fluid was under atmospheric pressure. The lumbar cerebrospinal fluid, at first blood-stained, returned to normal within three weeks, the highest pressure ever recorded being on the second day, when it was $250 \mathrm{~mm}$. water. Lung infection and respiratory obstruction gave rise to anxiety during the first week and a tracheostomy was made on the eleventh day.
The physical signs remained essentially unchanged until her death. The "brain-stem attacks" subside $\mathbb{P}$ after a fortnight. The patient had a quadriparesis complete in the left leg and more marked in the left arris than the right. All limbs were spastic though the ton varied from day to day; the tendon reflexes were usuallyo brisker on the right, and both plantar responses remainee extensor. Later in her illness the patient had attacks of sudden pyrexia with profuse sweating and hyperpnoeæ. and during these she would look very anxious an frightened.

The patient began to open her eyes after two week and soon lay awake for most of the day, sleeping at night. She first spoke definitely after 16 weeks. Five months after the accident she could answer and aste. simple questions, showing marked perseveration; sh recognized her relatives and was able to count to 10 im English, French, and German. When asked to dơ anything which was beyond her ability she would shout and scream. She was very moody and although able to take her food by mouth after four months, she refusent to eat at times and then had to be tube fed. She remainee doubly incontinent.

Her nutritional state remained good; she neves menstruated. She developed calcification in manit muscles. Her hair, which had been shaved for thes exploratory burr-holes, did not grow again until the fifth month, at which time she also showed the maxing improvement in her mental state. This improvement oras maintained for about three months after which \&he became increasingly mute and apathetic. She died quietly 318 days after the accident.

Investigations. - Right and left carotid angiograms 迸在 normal.

Ventriculograms made on the 13th and 183rd $\frac{0}{4 a}$ showed at first slight, then moderate ventricular dilatation especially of the right temporal horn; the aqueduct and fourth ventricle were normal.

Plasma proteins, serum electrolytes and calcium, ar blood urea were found to be within normal limits on numerous occasions.

The clinical diagnosis was " midbrain injury".

Post-mortem Findings in Case 2 (P.M. 10/52)

Macroscopic.-The patient was a well develope衰 well nourished young woman. Apart from eary bronchopneumonia the internal organs showed in macroscopic or microscopic abnormalities. Many muscles were calcified. There was no evidence fracture of the skull and the dura was normal.

The brain showed few macroscopic signs of injuris, either externally or on coronal section (Fig. 19. There were superficial cortical contusions at the base in the right occipitotemporal region, and little yellowing of the leptomeninges in relation the right occipital burr-hole. The lateral and third ventricles were moderately dilated, but the aquedurt and fourth ventricle were normal. There was $\mathfrak{a}^{2}$ softening in the right amygdaloid nucleus and a fes 


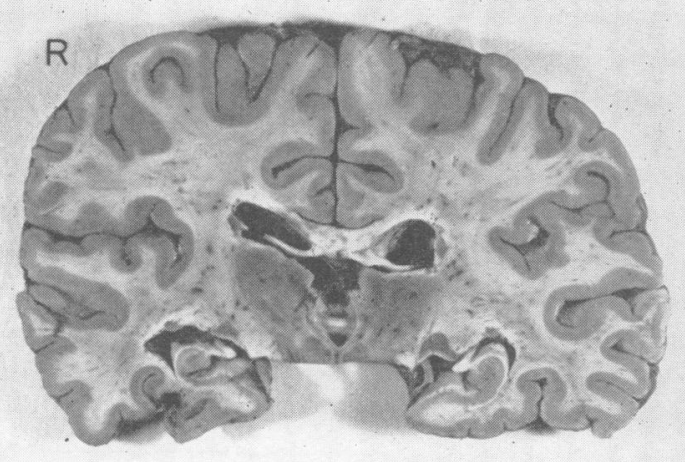

Fig. 19

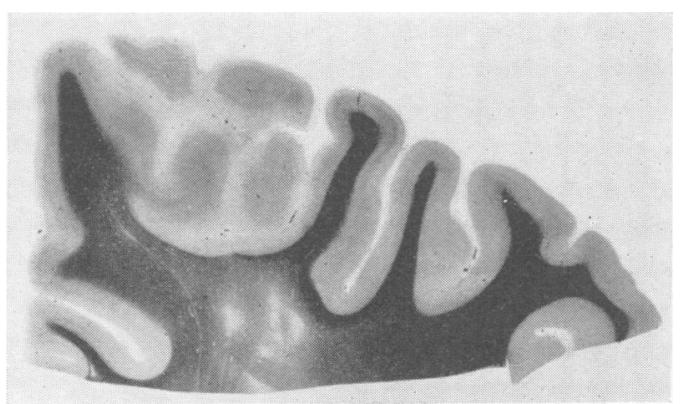

Fig. 20

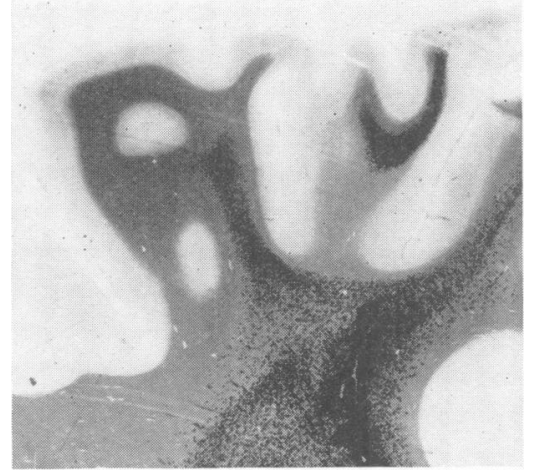

FIG. 21

FIG. 19.-Case 2: Coronal section through the hemispheres. Note the dilatation of the ventricles, the atrophy of the thalami, the superficial contusions on the under surface of the right temporal lobe, and the softening in the right side of the corpus callosum. Otherwise the brain looks normal ( $c f$. Figs. 20 and 21).

FIG. 20.-Case 2: Left motor cortex. Section from a block taken from the brain slice shown in Fig. 19. There is severe degeneration of the white matter underlying the motor cortex. Weil, $\times 1 \cdot 5$.

Fig. 21.-Case 2: Region of the right motor cortex. Section from a block taken from the brain slice shown in Fig. 19. Degeneration products are seen in the white matter. Marchi, $\times 1.6$.

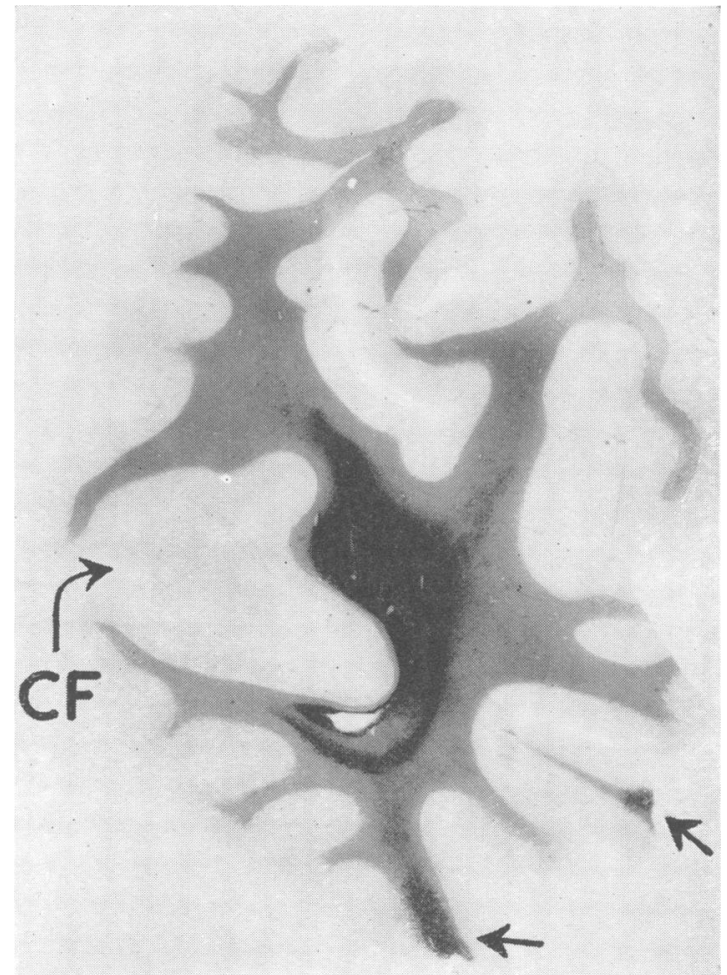

Fig. 22

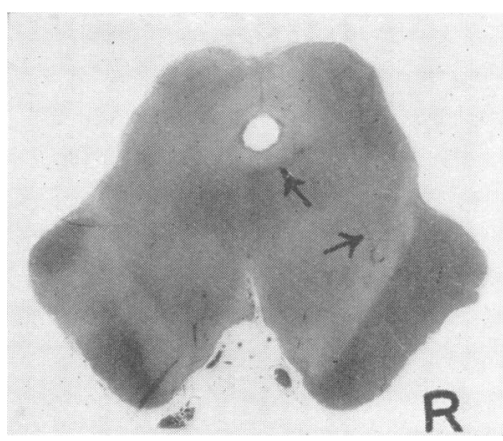

Fig. 23

FIG. 22.-Case 2: Coronal section through the right occipital lobe, stained with the Marchi technique. There is degenertion in the external and internal sagittal strata, in the forceps major, and in the rest of the white matter. There are two cortical contusions (arrows). $(\mathrm{CF}=$ calcarine fissure.) $\times 1.5$.

FIG. 23.-Case 2: Section of the midbrain showing a small scar in the peri-aqueductal grey matter and another in the right substantia nigra (arrows). There is degeneration in the middle part of the left and the lateral part of the right basis pedunculi. The left medial lemniscus is degenerated but this is difficult to see with this stain. The two dark lines in the left basis pedunculi are due to folds in the section. P.T.A.H., $\times 1 \cdot 8$. 
small foci of yellowing were scattered throughout the white matter and basal ganglia of both hemispheres. An old haemorrhage in the right side of the corpus callosum was also seen. There was a little cortical atrophy. The lower brain-stem appeared slightly shrunken. There were three areas of orangeyellow pigmentation $0 \cdot 1$ to $0.2 \mathrm{~cm}$. diameter in the midbrain and pons. A softening, $0.5 \mathrm{~cm}$. long, was present in the right superior cerebellar peduncle. No abnormality was noted in the spinal cord.

Microscopic.-The findings are as follows:-

Cortex and Underlying White Matter.-No abnormalities were detected in the cerebral cortex, apart from a few small cortical infarcts and the superficial contusions noted macroscopically. The white matter showed severe degeneration (Figs. 20 and 21) throughout most of both hemispheres (see Table II for distribution of degeneration). The optic radiations (Fig. 22) are not involved ( $c f$. Case 1) but there are fat granule cells in the left optic tract.

Basal Ganglia: Thalamus.-The dorsomedial nuclei are the best preserved. Compound granular corpuscles, cell loss, and gliosis are present in the lateral nucleus, the anterior nucleus, and are less marked in the pulvinar of both sides. These changes are more marked on the left. The lateral geniculate bodies are normal.

The corpus striatum shows a few small old haemorrhages. There are pseudo-calcareous deposits and some extracellular fat in the globus pallidus. There is a softening in the right amygdaloid nucleus going into the uncus. The hypothalamus looks normal.

Small haemorrhages and softenings, rather more numerous than in Case 1, are seen throughout the areas of affected white matter including both internal capsules. They are not, however, considered sufficient to account for the degree of degeneration.

Lower Brain-stem and Spinal Cord.-The degeneration in the descending tracts affects the cortico-spinal fibres on the left much more than on the right, and it can be traced into the spinal cord. The fronto- and temporo-pontine fibres are more affected on the left. Other tracts affected are shown in Table II. Serial sections through the pons failed to show any lesions to account for the degeneration of the medial lemnisci, the central tegmental tracts, or the medial longitudinal bundles.

There is a little gliosis in the sensory nucleus of the right fifth nerve and a few compound granular corpuscles are in the mesencephalic root of the right fifth nerve. There is a little superficial damage at the

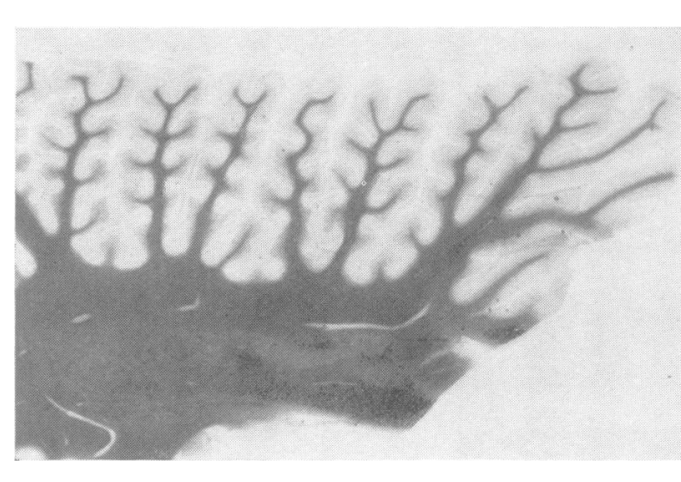

FIG. 24.-Case 2: Left cerebellum showing degeneration in sor of the folia and of the fibres in the neighbourhood of the dentare nucleus. Marchi, $\times 2$.

right upper border of the pons, where the transverse pontine fibres show some degeneration.

There is an old haemorrhage in the pontine tegmentum just lateral to the left medial longitudina bundle, and two glial scars in relation to mediunp sized blood vessels, one in the right substantia nigra the other in the right peri-aqueductal grey mattixip (Fig. 23). The whole peri-aqueductal region and $\bar{\phi} h \overrightarrow{\mathrm{s}}$ superior colliculi appear more cellular than norrfaf

In the floor of the fourth ventricle and throughout the pons there are small, very recent, evideat $\vec{y}$ terminal haemorrhages. These are the only evidence of recent pathological changes seen in the braing

Cerebellum.-The white matter is a little thinged and material staining with Marchi is seen in soms folia and near the dentate nucleus (Fig. 24).

Blood Vessels.-These were examined with care and no abnormality was found in them.

\section{Case 3}

G. T., a man aged 40, eight months before death wa knocked off his bicycle and immediately becamet unconscious. He sustained a compound fracture of the right tibia and fibula, and several lacerations of thevertex of the head and the left forehead from which he was bleeding when seen at the Radcliffe Infirmary oneand a half hours after the accident. The patient was then still deeply unconscious, barely responding to painful stimuli. He was severely shocked, the blood pressure being $60 / 30 \mathrm{~mm}$. $\mathrm{Hg}$, but this rose to normap. after blood transfusion. By the next day pulse, respira? tions, and pupillary reactions were normal, the corneas reflexes were present, and both plantar responses weres extensor.

Lumbar puncture on the third day showed a slightly blood-stained fluid under normal pressure. For the first: four days the patient was very ill because of atelectasis and infection of both lungs and a tracheotomy was performed 24 hours after the accident. He lay motionless and unresponsive for many weeks, hardly moving his 


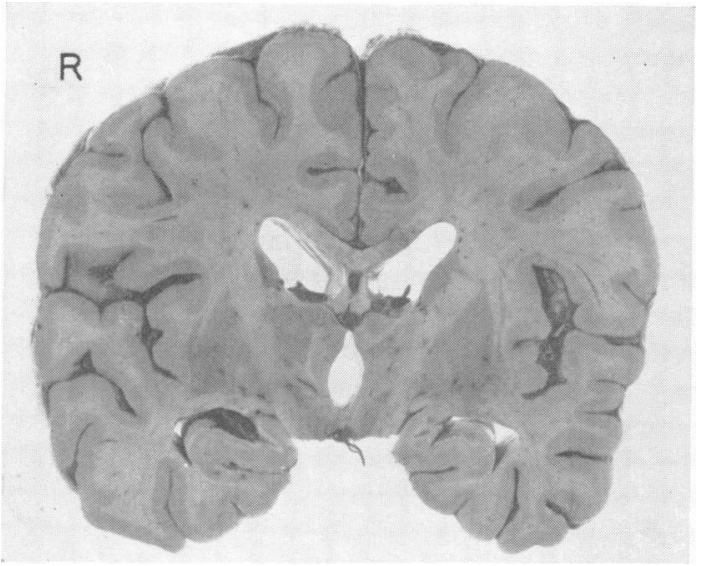

FIG. 25

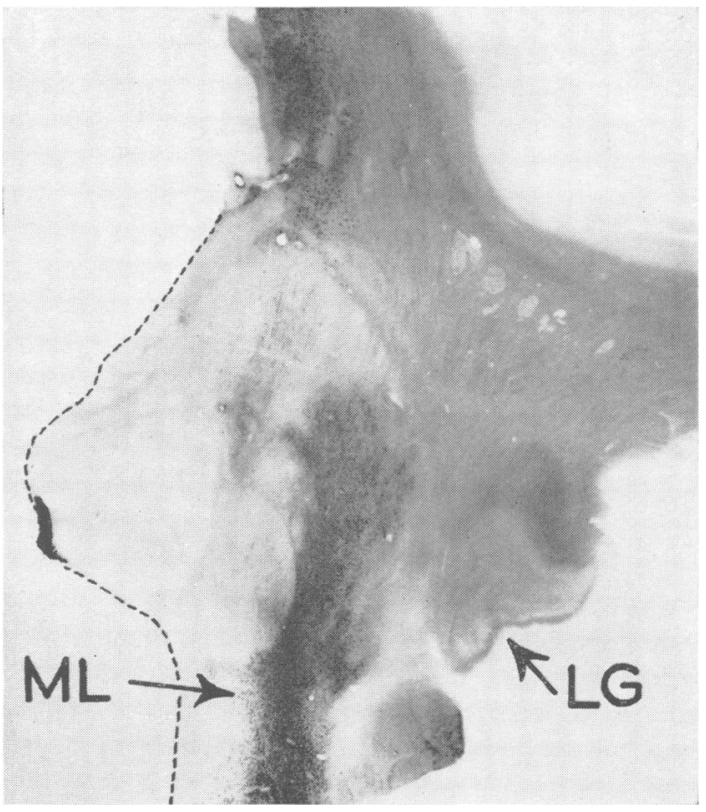

FIG. 27
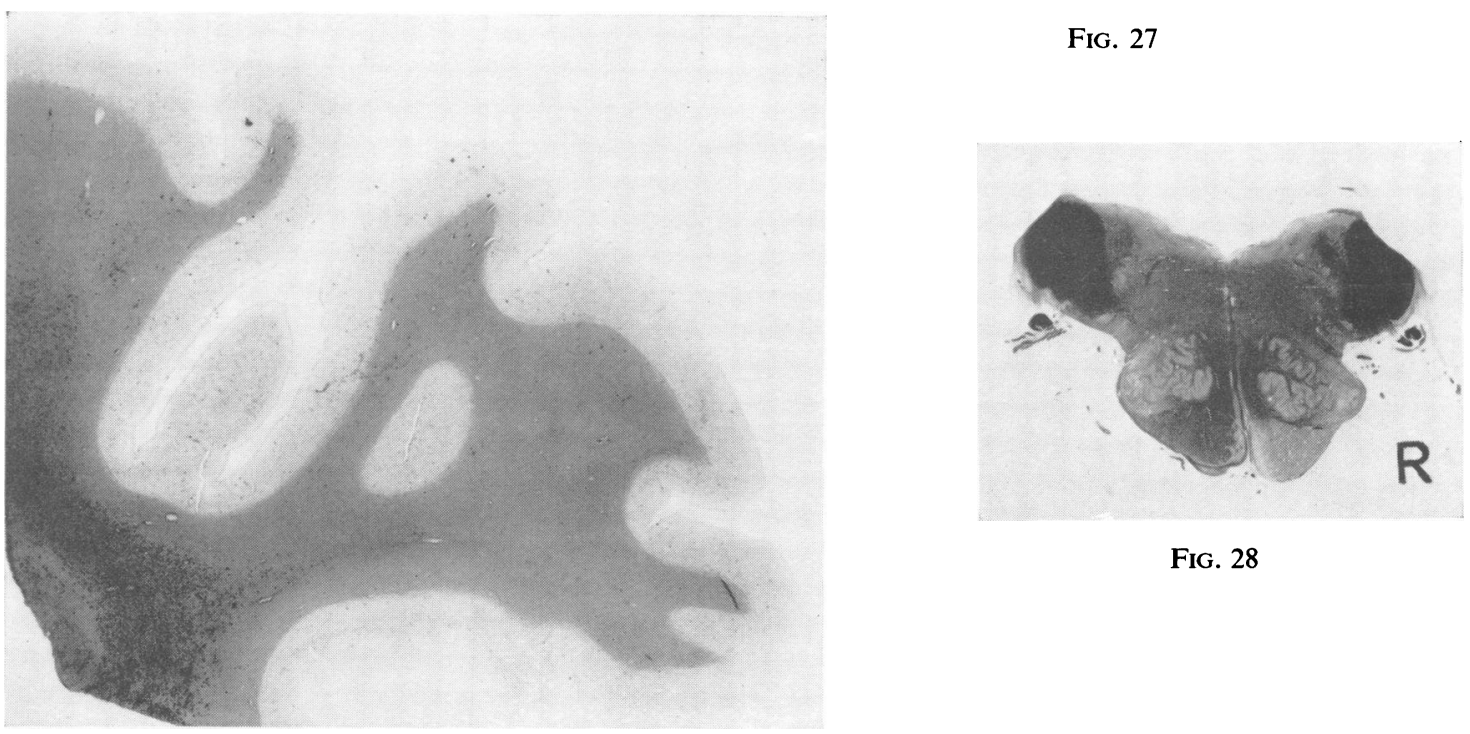

FIG. 28

Fig. 26

Fig. 25.-Case 3: Coronal section through the hemispheres showing slightly dilated ventricles, atrophy of the thalami, and a softening in the left side of the corpus callosum. The brain looks normal otherwise.

FIG. 26.-Case 3: Section from the left parietal region of the brain slice in Fig. 25, showing degeneration products in the white matter. Marchi, $\times \mathbf{1} \cdot 5$.

Fig. 27.-Case 3: Coronal section through the right thalamus and lateral geniculate body stained with the Marchi technique. The
FIG. 27 (cont.)-degenerated medial lemniscus can be seen entering the ventral postero-lateral nucleus of the thalamus. There is degeneration in the postero-lateral nucleus and in the rostral stalk (above). Note that the compound granular corpuscles lie in rows. ( $L G=$ lateral geniculate body; $M L=$ medial lemniscus. The dotted line represents the outline of the thalamus.) $\times 2 \cdot 5$.

FIG. 28.-Case 3: Section through the medulla to show the degeneration of the right pyramid, the arcuate fibres, and the central tegmental tracts (lateral and posterior to the inferior olives). Weil, $\times 2$. 
limbs even to painful stimuli (the right leg was in plaster).

After three weeks he began to open his eyes; after seven weeks he was able to obey simple commands, but only used the right hand for voluntary actions. At this time it was thought that the tendon reflexes on the left were a little increased and that the left leg was slightly spastic. Eleven weeks after the injury the patient began to speak a few words and was able to take semi-solid food by mouth slowly. His response to pain always remained sluggish.

This patient became extremely wasted and developed bed sores in spite of an adequate diet and expert nursing care. He developed oedema of the hands for which no cause was found and also calcification in many muscles. He died of bronchopneumonia 250 days after the accident.

Investigations.-Ventriculograms five and 18 weeks after the accident showed first slight, then moderate, ventricular dilatation. The aqueduct and fourth ventricle were normal.

Repeated estimations of plasma proteins, serum electrolytes and calcium, and blood urea were normal.

The clinical diagnosis of brain-stem injury was made.

Post-mortem Findings in Case 3 (P.M. 218/53)

Macroscopic.-The body was very emaciated and had several bed sores. The left knee was fixed in semiflexion and there was a healed fracture of the right lower leg. There was calcification of many muscles. Well-marked bronchopneumonia and a small stone in the left kidney were the only abnormalities found in the internal organs.

There was no evidence of fracture of the skull, and the dura, venous sinuses, and blood vessels at the base of the brain were normal.

No external abnormality of the brain was noted. Coronal sections showed moderate dilatation of the lateral and third ventricles (Fig. 25). There was a yellow softening in the left side of the corpus callosum, a little yellowing of the right uncus, a small area of yellowing in the right thalamus, and one in the left parietal region.

The aqueduct was slightly dilated and there were a few old softenings 0.1 to $0.2 \mathrm{~cm}$. diameter in the tegmental region of the midbrain.

Microscopic.-The findings are as follows :-

Cortex and Underlying White Matter.-The cortex looks normal in all areas examined. Degeneration of the white matter (Fig. 26) is well marked (see Table II), and on the whole is more severe in the left hemisphere ( $c f$. descending tracts).

A small softening abuts on the lateral part of the posterior limb of the right internal capsule.

Basal Ganglia: Thalamus.-The dorso-medial, anterior and centre median nuclei, and the right pulvinar appear more or less normal. All other regions show cell loss with gliosis and fat granule cells (Fig. 27).

Corpus Striatum.-This contains a few small, ol haemorrhages. There is slight gliosis of the leff globus pallidus and a superficial softening of the right uncus. The hypothalamus looks normal.

Lower Brain-stem.- In spite of the fact that the damage in the left hemisphere is more severe than that in the right, the corticospinal fibres are only. degenerated on the right, being almost completel spared on the left (Fig. 28). On the left the fronto pontine tract only is affected. At the upper end of the pons there is degeneration at the right latera悉 margin of the brain-stem.

This case shows more old brain-stem haemorr hages than the others. There is one about $0.3 \times 0.02$ and $0.5 \mathrm{~cm}$. long, and three smaller ones in the tegmental region of the midbrain, one $0.2 \mathrm{~cm} \cdot \overrightarrow{\vec{H}}$ diameter, and several very small ones in the basath part of the pons, and one in the left superio cerebellar peduncle.

Spinal Cord.-Many anterior horn cells show chromatolysis. There is degeneration in the left. lateral and right anterior columns.

Cerebellum.-There is a slight loss of Purkißipje cells. A little degeneration can be seen in the wheste matter of some of the folia and round the dentate nucleus.

\section{Case 4}

J. M., a man aged 27, was involved in a road accidênt 15 months before death. When seen an hour later $\$$ e

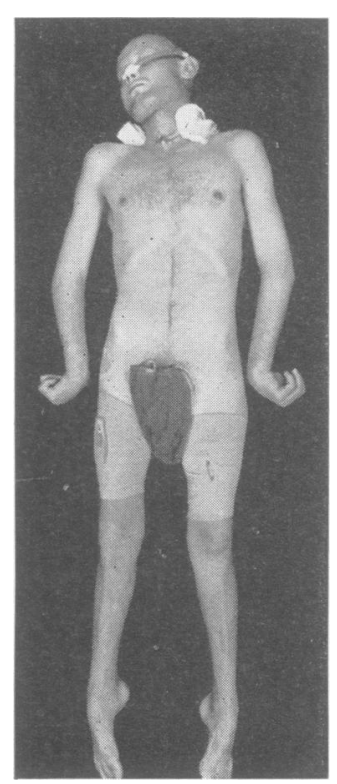
was comatose and the pupils although small and equap did not react to light. He improved steadily and two

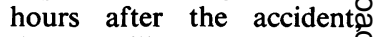
though still unconscious, he्ष responded to painful stimuli and blood pressure, pulse respirations, and pupillary reactions were normal. There were abrasions on the righp ear and a haematoma on the right temple and the right shoulder. Four hours afte? the injury he inhaled some vomit which caused sever respiratory distress for some 을

FIG. 29.-Case 4: This shows the patient during one of his "decerebrate" or "brain stem" attacks. The picture was taken six weeks after the accident. 

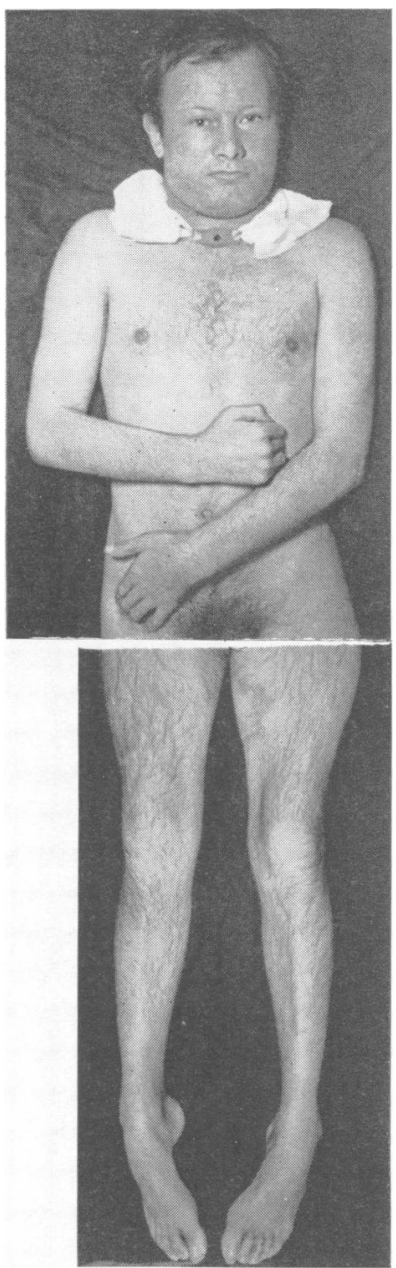

FIG. 30.-Case 4: This shows the same patient as in Fig. 29. He is here seen awake and lying in his usual posture. Photograph taken five months after the accident. minutes. His general condition deteriorated after this and he began to have attacks of decerebration(Fig. 29) accompanied by raised blood pressure. Exploratory burr holes were made 12 hours after the accident, when it was found that the brain looked normal, that the intraventricular pressure was not increased but that the cerebrospinal fluid was lightly blood-stained. The patient then passed through a period of hyperthermia which was controlled with an iced water rectal drip. Repeated lumbar punctures showed that, although the pressure was usually normal, on one occasion 48 hours after the accident it was $400 \mathrm{~mm}$. water. On the fourth day the patient opened his eyes and groaned in response to pain. Both lungs, however, showed evidence of consolidation and he was frequently cyanosed. It was not until a tracheotomy was made on the tenth day that the chest infection was brought under control. On the ninth day ventriculography was carried out to exclude a space-occupying lesion. The intraventricular pressure was somewhat increased (the patient's respirations were very laboured at the time) but the ventricles showed a slight symmetrical dilatation and there was no evidence of an intracranial clot.

After three weeks the patient lay in the attitude shown in Fig. 30, with feet plantar flexed, legs extended, arms flexed; the tone in the limbs was normal except at the ankles where it was much increased. He lay with his eyes open most of the time, following moving objects round the room; he yawned, swallowed, and grimaced in response to pain, when it was seen that there was no facial weakness. A little later it was said that he dis- tinguished between people he liked and those he disliked. At this time he began to use the left hand voluntarily, but not the right. This relative improvement was accompanied by an increase in spasticity of all limbs more marked on the right. He still had occasional " brainstem attacks" lasting up to two hours in which he assumed a decerebrate posture accompanied by profuse sweating and a high blood pressure (Fig. 29). He never spoke or obeyed commands. After six months he was transferred to another hospital where he died, having become rather thin, 450 days after the accident.

Ventriculograms.-On the ninth day there was very slight ventricular dilatation. After 12 weeks there had been a slight increase in the size of the lateral and third ventricles. The appearances were unchanged after 28 weeks.

Post-mortem Findings in Case 4 (P.M. 464/50)

Macroscopic.-The body was emaciated. Except for bronchopneumonia the internal organs were normal. There was no evidence of fracture of the skull; the dura and venous sinuses were normal. The cerebral hemispheres looked normal externally, though the pons and medulla were slightly shrunken, particularly on the left. The cerebellum was markedly wasted and firmer than normal. The blood vessels at the base of the brain were normal.

The occipital and frontal lobes were cut coronally, the rest of the brain horizontally. There was slight ventricular dilatation. Areas of yellowing were present in the posterior part of the corpus callosum on the right, with yellowing of the roof of the right lateral ventricle; there were streaks of yellow pigmentation in the white matter of the right temporal lobe, a superficial softening in the right uncus, a few small areas of yellowing in cortex and white matter, particularly in the parietal regions, and a cyst, $0.3 \mathrm{~cm}$. diameter, in the right caudate nucleus. There was a similar cyst in the white matter of the left cerebellar lobe. The lower brainstem showed a few minute yellow areas in the right tegmental region.

Microscopic.-The following are the main findings:-

Cortex and Underlying White Matter.-In general the cerebral cortex looks normal. There are a number of small cortical infarcts, rather more numerous than in the other cases, each confined to the bottom of a sulcus (Fig. 31), often affecting the deeper layers of cortex only. There is probably a slight cell loss in areas where the underlying white matter is much damaged. Ammon's horn is normal on both sides.

The white matter lesion (Fig. 31) is very severe in this case (see Table II), although some convolutions and the left frontal pole are spared. There is a 


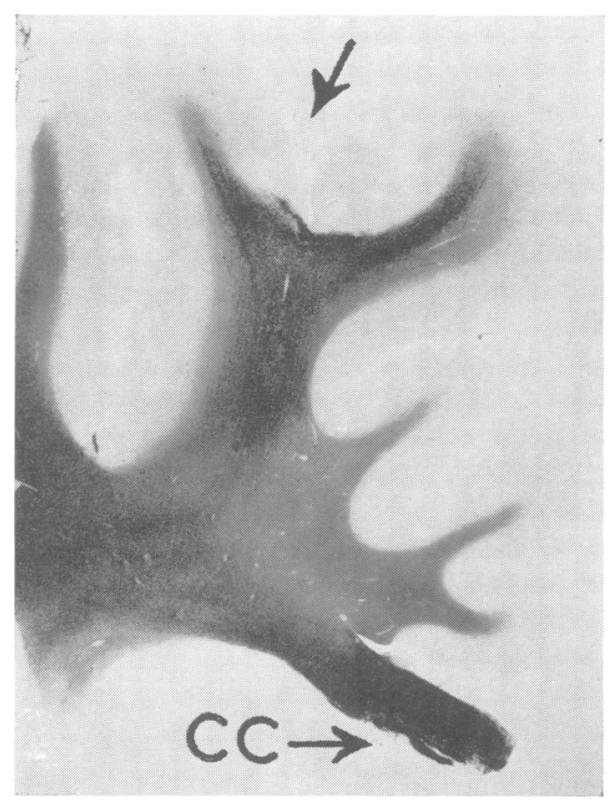

FIG. 31

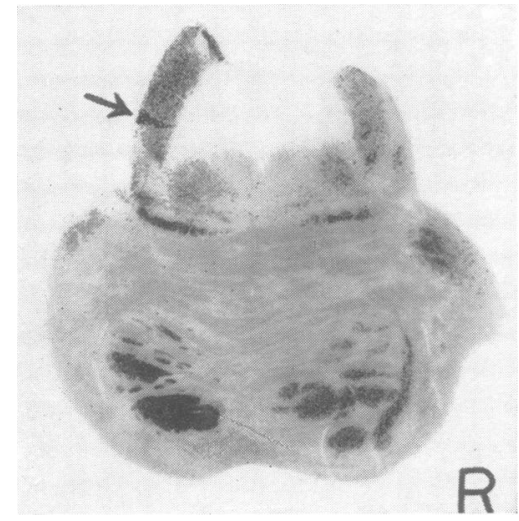

FIG. 33

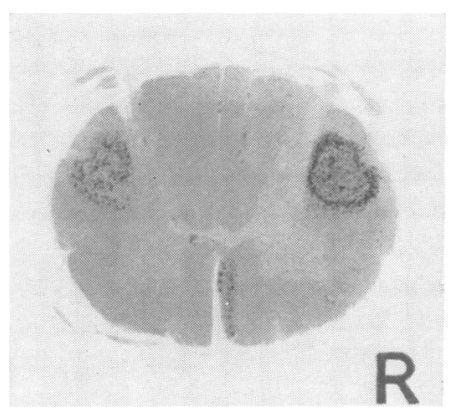

FIG. 34

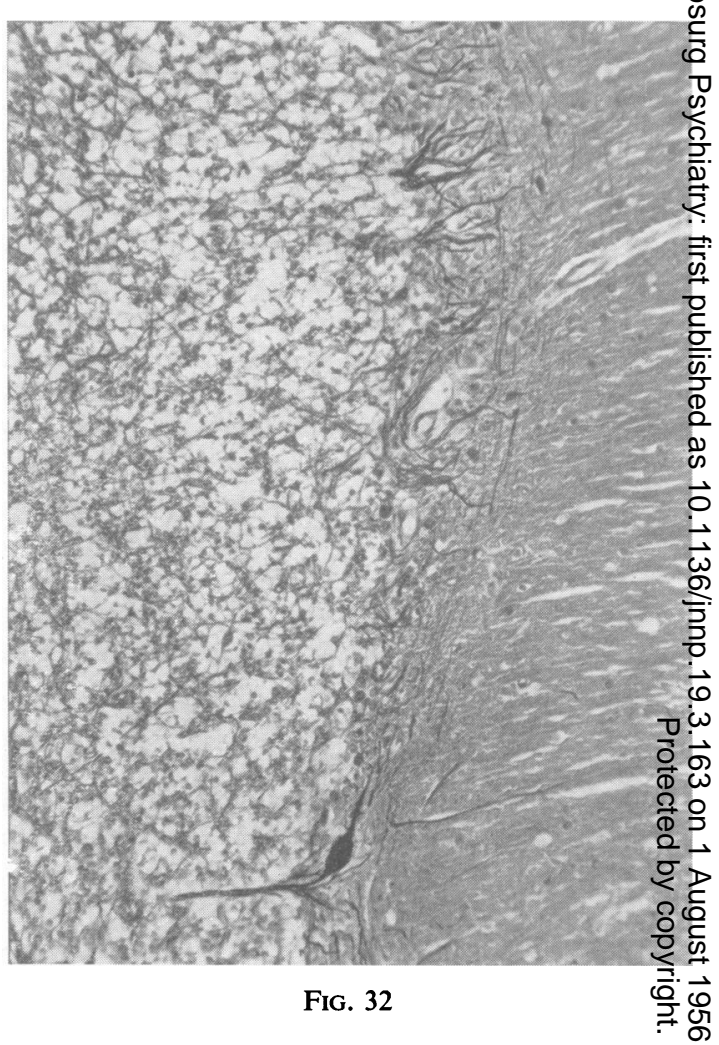

FIG. 31.-Case 4: Right parietal region stained with the Marchi technique. There is well-marked degeneration of the white matter, sparing the two convolutions above the corpus callosur (CC). This is severely degenerated. A cortical infarct is seen at the bottom of one sulcus (arrow). $\quad \times 2.4$.

Fig. 32.-Case 4: Section of the cerebellum. There was an almost total loss of Purkinje cells. This section shows a " torpedo" an $\bar{\Phi}$ several “ empty baskets". Glees' silver stain, $\times 153$.

Fig. 33.-Case 4: The pons stained with the Marchi technique There is degeneration in the descending tracts, the fifth nerveș the medial lemnisci, the lateral lemnisci, the central tegmenta. tracts, the superior cerebellar peduncles, and a bundle on transverse fibres. Notice that the fat granule cells still lie neatl in their tracts, although the injury occurred 15 months before death. Apart from a haemorrhage (arrow) in the left superion cerebellar peduncle there were no haemorrhages or softenings in. midbrain, pons or medulla. $\times 2 \cdot 1$.

FIG. 34. - Case 4: Spinal cord showing degeneration in both crossee and the right uncrossed pyramidal tract. Marchi, $\times 3 \cdot 75$. 
softening, about $0.5 \mathrm{~cm}$. diameter, in the posterior third of the left internal capsule, just before it enters the basic pedunculi.

Basal Ganglia.-There are marked changes in the thalami, particularly in the lateral and ventral nuclei, leaving the anterior and dorsomedial nuclei, the posterior part of the pulvinar, and the lateral geniculate bodies almost normal. The corpus striatum contains a few old haemorrhages. There is a slight gliosis in the left globus pallidus. The hypothalamus looks normal.

Cerebellum.-There is an almost total loss of Purkinje cells except in the vermis. Many of the remaining cells show swellings (torpedoes) on their axons (Fig. 32). There is a marked proliferation of Bergman cells. The white matter is demyelinated, and in Marchi preparations compound granular corpuscles are seen in the white matter of the folia where they are collected opposite the sulci of cerebellar cortex; in the central white matter they are found chiefly surrounding the dentate nucleus, which shows cell loss and gliosis.

Lower Brain-stem.-The degeneration of the descending tracts is considerably less severe on the right where some bundles are quite normal. Marchi preparations of the pons (Fig. 33) show the affected tracts which are also listed in Table II. The degeneration in the medial lemnisci is present from the upper medulla upwards. There is slight gliosis in the gracile and cuneate nuclei, in the sensory nuclei of the fifth nerves, and in the substantia nigra. There is marked cell loss and gliosis in the inferior olives. Some of the transverse bundles of pontine fibres are degenerated (Fig. 33). The surface of the inferior colliculi shows evidence of old haemorrhage and there are a few iron-containing macrophages in the basal part of the pons.

Spinal Cord.-There is degeneration in the right and to a less extent the left lateral columns; the anterior column is degenerated on the left side only (Fig. 34).

\section{Case 5}

A. T., a woman, aged 73 , a pedestrian, was knocked down by a motor cycle five months before death. When first seen shortly after the accident, she was unconscious, but moved the right arm in response to painful stimuli, and shortly afterwards all four limbs. The blood pressure was $130 / 90 \mathrm{~mm}$. $\mathrm{Hg}$, which was normal for her; pulse, respiration, pupillary reactions, and corneal reflexes were normal. She had a laceration on the right forehead and had fractured the left clavicle and the left femur. The limbs were flaccid. The patient gradually reacted more to painful stimuli, the right limbs moving better than the left. On the seventeenth day the tone of the right limbs was found to be increased, though the tendon reflexes were equal on the two sides. She lay immobile most of the time. On the tenth day she began to open her eyes and on the 74th day she first spoke definitely, though her vocabulary remained limited to a few words. She was able to obey simple commands. She was doubly incontinent and required tube feeding throughout her illness. The left shoulder was subluxated and she developed calcification in the surrounding muscles. Her state of nutrition remained good, but she developed sacral bed sores and died of bronchopneumonia 142 days after the accident.

Investigations. - Lumbar puncture on the fourth day and on several subsequent occasions showed a normal cerebrospinal fluid pressure. A right angiogram made on the 35th day was normal.

\section{Post-mortem Findings in Case 5 (P.M. 271/49)}

Macroscopic.-The body was well nourished; there were small bed sores on both heels and a large one over the sacrum. There was a large callus in the middle of the shaft of the left femur and on the left clavicle. There was tracheitis and hypostatic pneumonia in both lungs. There was an old perinephric haematoma near the right kidney.

There were no fractures of the skull and the dura was normal.

The brain was injected in situ with bismuth bicarbonate in formalin, via the carotid arteries. This produced marked swelling of the brain, particularly of the right hemisphere. Radiographs of the brain made afterwards showed normal vessels.

There was a translucent membrane, $5 \mathrm{~cm}$. diameter, over the left frontal lobe, probably the remains of a thin subdural haematoma. The vessels at the base of the brain were healthy. The size of the ventricles could not be judged because of the artefactual brain swelling. The only abnormality noted on the coronal sections was a cortical contusion in the right parietal region. The brain-stem and spinal cord were normal, except for minute flecks of yellowing in the left superior cerebellar peduncle.

Microscopic.-The injection mass made the cutting and interpretation of celloidin and paraffin sections difficult. The Marchi method was found to give the most satisfactory preparations for examination.

Cortex and Underlying White Matter.-Except for the contusion in the right parietal region which was noted macroscopically, the cortex appears normal in the areas examined. This contusion occupies the summit and side walls of the convolution (Fig. 35). There are softenings in Ammon's horn on both sides. The white matter shows severe degeneration in most areas (Table II and Fig. 35). Occasional retraction bulbs and abnormal nerve fibres are seen in the 


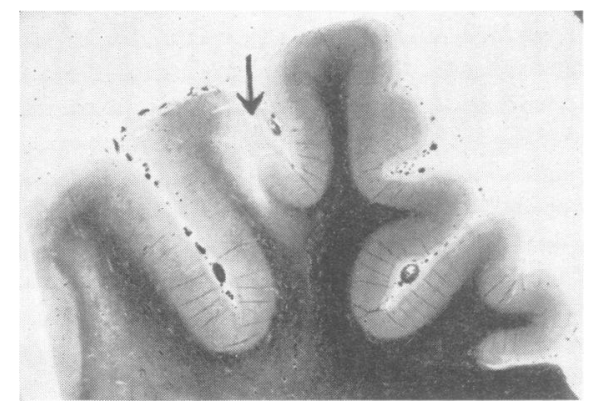

FIG. 35

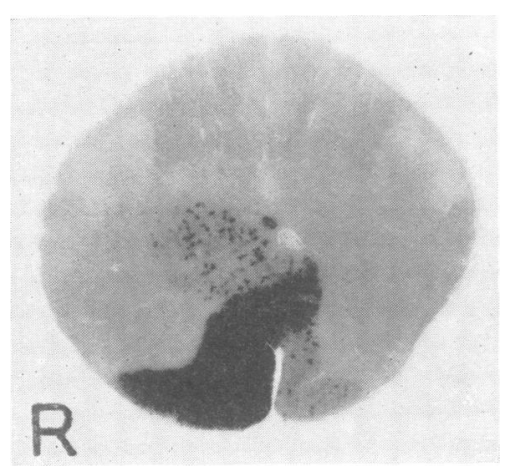

FIG. 36

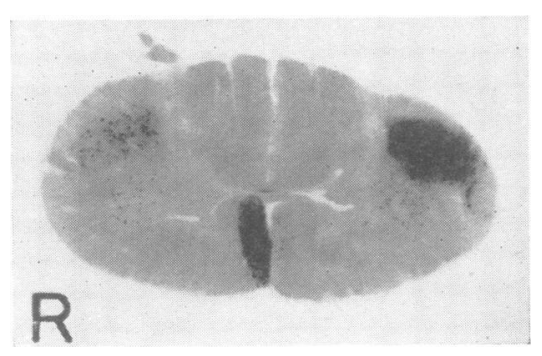

FIG. 37

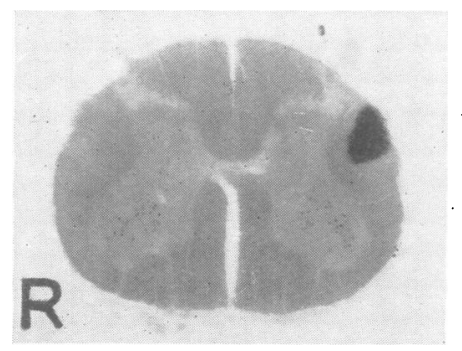

FIG. 38
FIG. 35.-Case 5: Right parietal region showing degeneration of the white matter and the only cortical lesion (arrow) found in this brain. The small white spots are not focal lesions but artefacts occurring in abnormal white matter. Weil, $\times 1 \cdot 7$.

Fig. 36.-Case 5: Medulla showing degeneration in the decussating pyramids. Marchi, $\times 3 \cdot 8$.

Fig. 37.-Case 5: Spinal cord in the cervical region showing unequa degeneration in the crossed and direct cortico-spinal tracts The black spots in the anterior horns are due to staining of the lipochrome in the nerve cells. Marchi, $\times 3.8$.

FIG. 38.-Case 5: Spinal cord in the lumbar region. There degeneration in the left cortico-spinal tract. The degeneration in the right anterior and lateral columns has petered out. (c Figs. 36 and 37.) Marchi, $\times 3.8$.

right parietal region, in areas where there is n⿳亠丷 obvious focal damage.

Basal Ganglia: Thalamus.-The picture is difficulf to interpret, but there appear to be fat granule cell $\$$ and gliosis in the lateral nuclei and the pulvinar, right more than left. The lateral geniculate bodies are normal. The corpus striatum and hypothalamu这 look normal.

Lower Brain-stem and Spinal Cord.-Degeneratio $\vec{\oplus}$ of the cortico-spinal tracts is very much worse the right (Fig. 36, 37, and 38). The fronto-ponfing fibres are affected on the left. For degeneratob of other tracts see Table II.

Cerebellum. -There is some degeneration of the white matter of the folia of the upper half of the cerebellum and of the peridentate fibres, on be sides.

\section{SUMMARY OF THE FINDINGS}

흘 임

Five patients, four under 40 and one 73 years olp received closed head injuries without fracture of th skull which rendered them unconscious immediatelyo Within a few hours of the accident blood pressure respiration, and pupillary reactions were normab? but there were more or less marked signs of pyra midal tract involvement on one or both sides. Three of the patients were subject to attacks of decerebrap tion with rise in blood pressure and sweating. None of the patients developed significant intracrania haemorrhages or showed clinical evidence of oedema Three required tracheotomies. The patients did not recover normal consciousness but remained almos?. completely unresponsive, though they lay awake fós most of the day; they were in fact extremely demented All patients had a more or less spastic quadriparesis In this state they survived for five to 15 months.

The significant pathological features were. Tho brain looked normal macroscopically apart from. dilated lateral and third ventricles. Microscopicallo there were a few small softenings and haemorrhages, and a diffuse degeneration of the white matteo 
characterized by loss of nerve fibres and the presence of numerous compound granular corpuscles. The cerebral cortex was normal. There was secondary atrophy of the thalamus and asymmetrical degeneration in the long descending tracts. There was degeneration in the medial lemnisci and the central tegmental tracts, but no lesions were found to account for this. The main fibre tracts affected and the external marks of violence are summarized in Tables II and III. In addition there was degeneration in the anterior commissure, the fornices and the mammillo-thalamic tracts, and in the white matter of the cerebellum. Three cases had very small, old haemorrhages in the lower brain-stem. All cases had lesions in the corpus callosum and in one or both superior cerebellar peduncles.

\section{DISCUSSION \\ Interpretation of Histological Findings}

During the months which our patients survived the head injury, healing processes will have been occurring in the damaged brain and therefore the relation of the histological findings to the original damage will have to be discussed.

One of the surprising pathological features is the presence of so much lipid material at the time of death, and one has to consider whether the lesions now seen can have been produced near the time of the accident or whether there has been progressive pathological change. It is impossible to date pathological lesions with any accuracy and one can only say that all the lesions, whether focal or diffuse, look old and quiescent and of the same age, with the exception of very recent (terminal) haemorrhages. The fact that the breakdown products stain with the Marchi method even after long fixation in formalin can be taken to indicate that these lesions are at least several months old, since it has been shown by Smith (1956) that Marchi-positive material from recent lesions disappears on storage in formalin. Since, in addition, there is no clinical evidence of increase of neurological abnormalities it is likely that the damage found in these brains occurred at or near the time of the accident.

It seems also that very little distortion of the original picture has come about through migration of macrophages containing degeneration products into healthy regions. This is clear from the study of such areas as the brain-stem or the stalks of the thalamus where fat granule cells still lie in the tracts whose degeneration they represent, often in neat rows parallel to the fibre direction of the tract (Figs. 27 and 33).

Some of the breakdown products from the diffuse lesion have probably been absorbed, though much

TABLE II

DISTRIBUTION OF THE DEGENERATION IN THE FIVE

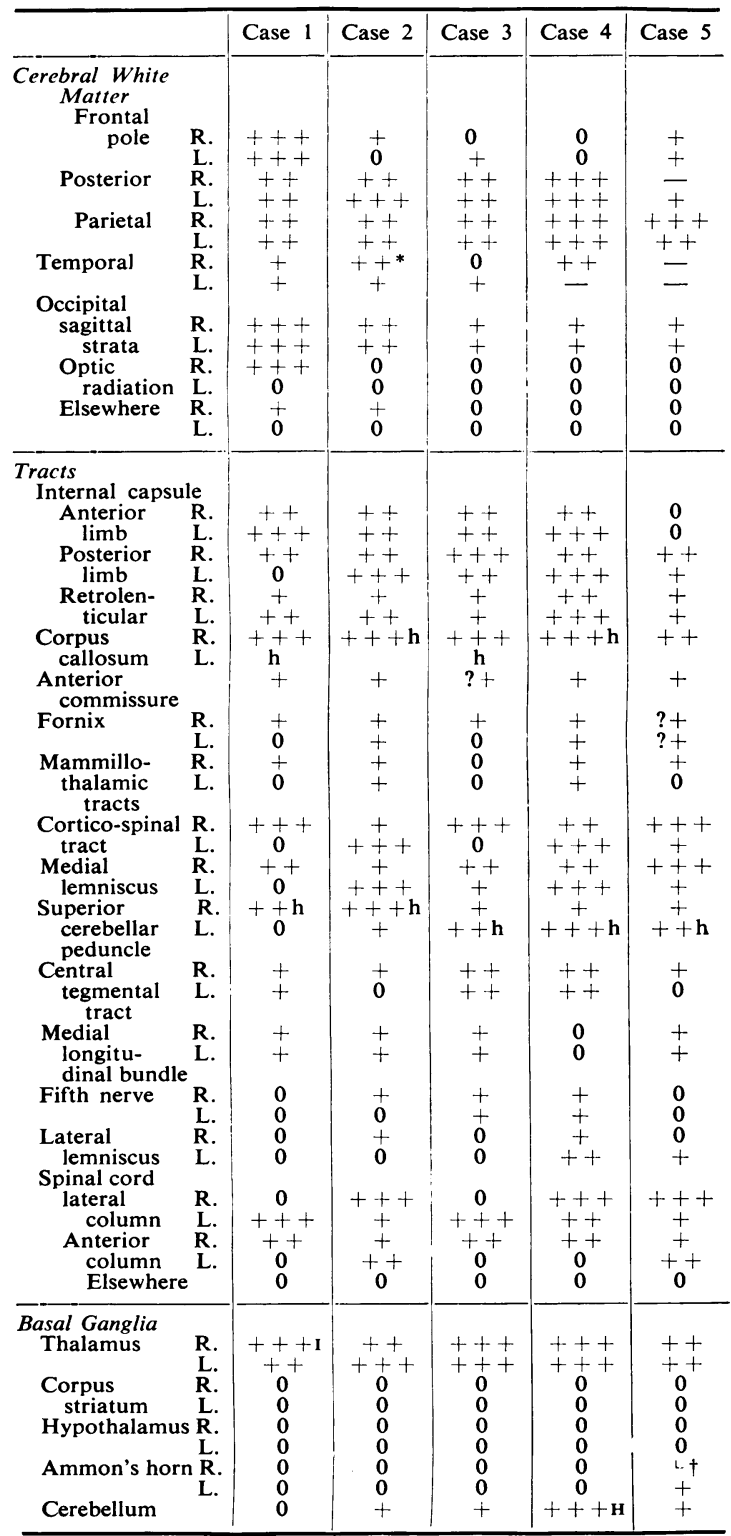

* = Cortical contusion

$\mathbf{h}=$ Haemorrhage

I = Left lateral geniculate body

degenerated

$\dagger=$ Bilateral necrosis
$\mathbf{H}=$ Total loss of Purkinje cells

$\begin{aligned}+++ & =\text { Severe degeneration } \\ ++ & =\text { Moderate degeneration } \\ + & =\text { Slight degeneration } \\ 0 & =\text { No degeneration } \\ & =\text { Not examined }\end{aligned}$

is clearly left. It is unlikely that any of the focal lesions have completely disappeared, as scars of very small haemorrhages and softenings are still visible (Fig. 4). 
TABLE III

THE PYRA MIDAL SIGNS AND THE SITE OF INJURY AND OF ASY M METRICAL LESIONS

\begin{tabular}{|c|c|c|c|c|c|c|c|}
\hline \multirow[b]{2}{*}{ Case } & \multirow[b]{2}{*}{$\begin{array}{l}\text { External } \\
\text { Injuries }\end{array}$} & \multirow[b]{2}{*}{$\begin{array}{l}\text { Motor } \\
\text { Signs }\end{array}$} & \multirow[b]{2}{*}{ Pyramid } & \multicolumn{3}{|c|}{ Degeneration or Haemorrhage in } & \multirow[b]{2}{*}{$\begin{array}{l}\text { Other } \\
\text { Regions }\end{array}$} \\
\hline & & & & $\begin{array}{c}\text { Medial } \\
\text { Lemniscus }\end{array}$ & $\begin{array}{c}\text { Corpus } \\
\text { Callosum }\end{array}$ & $\begin{array}{l}\text { Superior } \\
\text { Cerebellar } \\
\text { Peduncle }\end{array}$ & \\
\hline 1 & L. forehead, & Paralysis $\mathbf{L}_{\mathbf{R}}>\mathbf{R}$. & R. & R. & L. & R. & R. optic radiation \\
\hline 3 & $\begin{array}{l}\text { behind L. ear } \\
\text { Vertex } \\
\text { L. forehead }\end{array}$ & $\begin{array}{l}\text { Spasticity R. }>\mathbf{L} . \\
\text { Paralysis } \mathbf{L} .>\mathbf{R} \text {. } \\
\text { Spasticity } \mathbf{L}>\mathbf{R} .\end{array}$ & R. & R. & L. & $\mathbf{L}>\mathbf{R}$ & $\begin{array}{l}\text { R. uncus } \\
\text { Fifth nerves }\end{array}$ \\
\hline 5 & R. forehead & Paralysis $\mathbf{L} .>\mathbf{R}$. & Mainly R. & Mainly R. & $\begin{array}{c}\text { Midline } \\
\text { Splenium }\end{array}$ & Slight $\mathbf{R}$. & $\begin{array}{l}\text { L. lateral } \\
\text { lemniscus }\end{array}$ \\
\hline 2 & R. occipital & $\begin{array}{l}\text { Paralysis } \mathbf{L} .>\mathbf{R} \text {. } \\
\text { Spasticity } \mathbf{R} .>\mathbf{L} \text {. }\end{array}$ & Mainly L. & Mainly L. & $\begin{array}{l}\text { R. and Midline } \\
\text { Splenium }\end{array}$ & R. $>$ L. & $\begin{array}{l}\text { L. optic tract } \\
\text { R. uncus }\end{array}$ \\
\hline 4 & R. temple & $\begin{array}{l}\text { Paralysis R. }>\mathbf{L} . \\
\text { Spasticity } \mathbf{L} .>\mathbf{R} .\end{array}$ & L. $>\mathbf{R}$. & L. $>\mathbf{R}$. & R. & L. $>\mathbf{R}$. & $\begin{array}{l}\text { inferior surface of } \\
\text { R. temporal lobe } \\
\text { R. uncus } \\
\text { Fifth nerves } \\
\text { Lateral lemnisci }\end{array}$ \\
\hline
\end{tabular}

It is therefore concluded that the lesions seen at necropsy correspond fairly closely to the original lesions.

\section{Pathogenesis of Lesions}

This is not known, but evidence will be presented for the suggestion that distortion of the brain by mechanical forces plays a part in the production of the condition described. The factors to be considered apart from this are anoxia, oedema, vascular disturbances, and fat embolism.

Anoxia.-There is no definite clinical evidence that these patients were anoxic shortly after the accident and before the neurological signs appeared, except Case 4 who began to have decerebrate attacks after severe respiratory obstruction due to inhaled vomit.

The pathological lesions which are usually ascribed to anoxia are strikingly absent in our cases. Classically anoxia affects nerve cells in the cerebral cortex, Ammon's horn, the globus pallidus and the Purkinje cells in the cerebellum (Hoff, Grenell, and Fulton, 1945; Heymans, 1950; Courville, 1953b), and such changes have been described in fatal head injuries by Malamud and Haymaker (1947). Such nerve cell damage is not present in our cases except in two instances. Case 5, a 73-year-old woman, had bilateral necrosis of Ammon's horn, but as an isolated finding this cannot be taken as evidence of generalized anoxia (Spielmeyer, 1925). Case 4 had an almost total loss of Purkinje cells in the cerebellum, without anoxic changes elsewhere. There was also a softening in one cerebellar lobe and the whole cerebellar lesion may have been due to local disturbances of the blood supply, though hypoxia may have contributed to this picture since the patient was very cyanosed on several occasions.

It is true that white matter degeneration due to anoxia does occur, especially under experimental conditions and when the anoxia is due to poisons (Hurst, 1942; Lumsden, 1950, chronic cyanide poisoning; Meyer, 1928b, chronic carbon monoxide poisoning). It has also been described in humancarbon monoxide poisoning (Meyer, 1928a; Grinker 1925; Strecker, Taft, and Willey, 1927) and after nitrous oxide anaesthesia (O'Brien and Steegmanno 1938; Courville, 1953a, Case 10) but such cases are rare and nearly always show the more typica 9 changes of anoxia as well.

Anoxia is therefore not considered to have playedu a major part in the production of brain damage $\overrightarrow{0}$ the cases under discussion.

Oedema.-There can be no doubt that cereb swelling due to oedema occurs in head injures nor that long-standing oedema can prodwc demyelination. The view that such a mechanisno iळ important for the production of permanent brain damage after head injury has been put forwawder notably by Evans and Scheinker $(1944,1945)$. None of our cases had clinical evidence of oedema, thap is, there were no signs of raised intracranial pressure at any time and the lumbar or ventricular cerebro spinal fluid pressure when estimated during the first few days after the accident was within norma limits. It is difficult to believe that oedema severet enough to cause such extensive demyelination woul 9 have passed unnoticed clinically. The onset of decerebrate rigidity immediately after the injury (i Case 1 while still lying on the road) also makes oedema unlikely as the major factor.

The histology of the white matter in oedema as seen near tumours (Greenfield, 1939; Scholz, 1949) near abscesses, or after superior sagittal sinus thrombosis (Woolf, 1954) differs from that seen i⿱ our cases, particularly because fat granule cells are so few or absent in oedema.

It seems therefore that no good case can be made out for oedema as the cause for the white matte lesion.

Vascular Disturbances.-Lesions which are unN doubtedly due to interruption of the blood suppliv 
are seen in all the brains. They are the small haemorrhages and softenings, small cortical infarcts situated at the bottom of the sulci, and sclerosis of Ammon's horns in one case. These lesions are interesting but, it may be said at once, they are not sufficient to account for the degree of white matter change.

The question of the pathogenesis of these focal lesions must be left open at the moment. The view that they are due to a direct mechanical effect on blood vessels has been put forward by Bright (1831), Schmaus (1899), Jakob (1913), Denny-Brown and Russell (1941), and is favoured by the present author. Lindenberg (1955) has advanced the idea that they are due to compression of arteries by the swollen brain (or by pressure due to intracranial haematomata), but his arguments are not entirely convincing. There is also a school which believes that focal lesions and degenerative changes are due to malfunction of the vasomotor centre after concussion leading to stasis in the cerebral blood vessels with diapedesis of red cells or oedema and necrosis (Ricker, 1919; Marburg, 1936; Helfand, 1939; Courville, 1953a). Most of these authors base their arguments on the work of Ricker (1919). Ricker investigated the acute effect of trauma on blood vessels, using the rabbit's ear, mesentery, and pleura. $\mathrm{He}$ also studied the chronic effect of injury on the vascular system by observing the vessels of the pancreas after tying off its duct, and the effect of mesothorium irradiation on the vessels of the rabbit's ear. He then used the results of these investigations to infer what must be happening in the brain during, and in the weeks and months following, concussion. It is of great historical interest that he was able to do this without qualms, but such reasoning is no longer permissible.

There is no direct evidence that the focal or the diffuse lesions are due to vasomotor disturbances.

Fat Embolism.-There was no clinical evidence for this and the diffuse lesion is difficult to account for by such a mechanism. Fat embolism would be expected to produce focal areas of demyelination, such as have in fact been demonstrated experimentally by Woolf (1954).

Physical Injury.-The view that the degeneration of white matter is due to physical damage to nerve fibres at the time of the injury cannot be proved at present, but there is circumstantial evidence in its favour.

(1) Physical damage to the nervous system would account for the presence of permanent abnormal neurological signs so soon after the injury. (In the case of which there is an eye witness account, the signs were present within minutes if not seconds of the accident.)

(2) The histological picture is compatible with injury to nerve fibres severe enough to cause their death and secondary degeneration. The microscopic appearance of the diffuse white matter lesion is indistinguishable from that of known Wallerian degeneration in the same brain, e.g., distal to a haemorrhage or in the descending tracts in the brain-stem and spinal cord.

(3) The complete sparing of whole or parts of some convolutions in areas where the degeneration is otherwise severe, and the markedly unequal degree of degeneration in the two pyramidal tracts in the presence of bilateral hemisphere damage suggest a mechanical cause for the lesion and are difficult to account for on any other basis. It is unlikely that oedema or anoxia can affect fibres so selectively.

(4) Stretching and tearing of nerve fibres and blood vessels throughout the brain is a likely consequence of head injuries accompanied by rotation, which produces shearing strains and distortion of the brain (Holbourn, 1943, 1945). The exact injury will depend on " the degree of distortion, on the nature of the distorted region and on the directions of the shear strains relative to fibredirections" (Holbourn, 1945). These factors may account for widespread damage with sparing of some regions or some fibre tracts of the brain.

Some asymmetry such as the unilateral pyramidal tract degeneration is not unexpected (Holbourn, 1943, and personal communication) when the brain is rotated in a plane of symmetry, e.g., the coronal or the horizontal plane. This is due to the fact that the two hemispheres are mirror images of each other. When the brain rotates so that, say, one temporal lobe moves downwards, the other temporal lobe will move upwards; corresponding damage in the two hemispheres would only be expected if both temporal lobes moved downwards.

Some of the lesions seen in the brains under discussion are almost certainly due to physical injury, for example the haemorrhages in the corpus callosum and the softening in the superior cerebellar peduncles.

Details of the accidents are not known, but the external marks of violence and the lateralization of the lesions are shown in Table II. The number of cases is too small and the information too scanty to draw any conclusions.

It is difficult to account for the degeneration of the tracts, other than the long descending tracts, in midbrain and pons, which is seen in all the cases, but it seems possible that this also is due to 
disruption of nerve fibres at the time of the accident.

Thus there is much evidence in favour of mechanical damage as the chief cause for the lesions, though it is not conclusive.

\section{Clinico-pathological Correlation}

The most striking clinical features of our patients were the quadriparesis, usually spastic, and the grossly abnormal mental state. The patient in whom speech could be assessed was also aphasic. The mental state was characterized by an extreme indifference to the enviroment and by unresponsiveness except to crude stimuli. It may be tempting to refer to a patient in this condition as unconscious or comatose, but it is more correct that such patients should be called demented.

It is important to distinguish between these states if attempts at correlating the clinical picture with anatomical lesions are to be made, particularly perhaps to-day when much work is being done on defining the nervous centres necessary for the maintenance of consciousness.

The mental functions were not equally severely affected in all patients. One (Case 2) was able to ask and answer questions and recognized her relatives, two others (Cases 3 and 5) spoke a few words and obeyed simple commands. These three patients must have been conscious or aware of something in their environment. Two others (Cases 1 and 4) never spoke or obeyed commands, though apart from this their reactions did not differ from those of the first three patients. Patients 1 and 4 were so inaccessible that it is impossible to know whether they were conscious or not, but they (and the others) differ from comatose patients in several important respects.

Once the acute effect of the head injury had worn off, there was a clear difference between the waking and the sleeping state. They lay with their eyes open, looking round, for many hours at a time, even when not being stimulated.

They not only swallowed but chewed and were able to eat and drink though they could not feed themselves.

They blinked in response to menace. This reflex is one of the first to be lost when a patient is made unconscious by an anaesthetist.

They looked alert.

It would seem therefore that the two patients who did not respond to the spoken word were not more comatose than the three who did, but were even more demented.

Histological examination of the brain showed a severe diffuse degeneration of the white matter in the cerebral hemispheres, which had interrupted connexions between different areas of cortex, and between the cortex and the lower centres, and ha⿳ produced secondary atrophy of large parts of the thalamus. Such a lesion can account for a severif generalized loss of cerebral function such as was shown by our patients. The lesion is severest in the patients who were most demented, in whom mosid of the anterior three-quarters of the brain wete affected. The temporal and occipital regions weec. the least affected in all cases. In addition to the hemisphere lesion there was degeneration in the sensory tracts, that is, in one or both media्यु lemnisci in all cases, and in the lateral lemnisci of visual pathways in some, and this no doubt addeg to the indifference of the patients to sensory stimula tion.

The white matter degeneration presumably alş accounts for the quadriparesis seen in each patiene. It is interesting that there was paralysis and spasticitg bilaterally, although the degeneration in the two pyramidal tracts was markedly unequal in four cases. There was no correlation between the degree of paralysis or spasticity and the degree of pyramid tract degeneration. That there is this lack of correlation is well known, and the literature on this point has recently been reviewed by Lassek (1950)

Only two of the four patients with unequal popras midal tract degeneration lay in a strikingly as ofn? metrical posture (Fig. 18). In both, the side Reld in the so-called decerebrate position was innervate by the almost normal pyramidal tract.

So-called "brain-stem attacks" were obsere in three patients and in Rosenblath's (1899) câs During these the patient assumes the decerebrats posture (Fig. 29) and there is profuse sweating and a rise in blood pressure and respiratory rate. Nothin can be said about the lesions responsible for these attacks except that they need not be evidence midbrain haemorrhages.

Many features remain unexplained, among them are the non-neurological abnormalities which include the development of calcification of muscles in three out of five patients, the severe wasting in spite of a⿳亠二口犬 adequate diet in one, the complete absence of menstruation and the absence of growth of the haw for many months in another.

It will be apparent that the neurological abno malities were severe and complicated and that the lesion and its secondary effects were so widespread that a detailed analysis is difficult, if not impossible

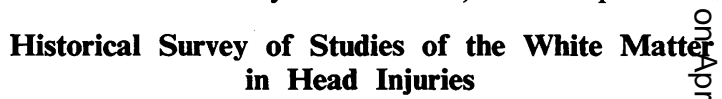

One hundred years ago it was clear to all worke that, as Gama (1835) for instance put it, " fibres delicate as those of which the organ of mind $\$$ composed are liable to break " as a result of violenes 
to the head. But in recent years little attention has been paid to the white matter in head injuries. This is partly because human pathological material from patients who survive an injury long enough for histological changes to develop is not readily available to neuropathologists, and also because slight or scanty changes are very difficult to see in the brain. Another reason is that experimenters have been mainly interested in concussion which is supposed to be either fatal or reversible, and not in mechanisms of brain injury which may leave neurological sequelae. Few head injury experiments with survival, which would be suitable to reveal damage to nervous tissue, are therefore on record.

One of the first long-term experiments was done by Witkowski in 1877 . Amongst other animals he used frogs which he stunned by hitting their heads against a table. After a few times this produced permanent changes such as unsteadiness, weakness, and lack of will power, a picture apparently reminiscent of human patients with general paralysis. Microscopical examination showed petechial haemorrhages in the brain substance, but staining methods were not then generally available.

Schmaus $(1890,1899)$ studied spinal cord concussion in rabbits produced by blunt injuries to the back. He found secondary degeneration of nerve fibres above and below the level of injury without obvious focal damage. This was later confirmed by Jakob (1913). Schmaus came to the conclusion that the nerve fibres died as a result of mechanical damage.

An important study was published by Jakob in 1913, who concussed rabbits and monkeys by letting a hammer of known weight fall on their heads from a known height. This procedure was repeated, sometimes on successive days, until permanent signs appeared such as clumsiness, nervousness, and loss of appetite. At necropsy diffuse degeneration of the white matter, which could not be accounted for by focal lesions, was found in the brains of all the animals which survived the injury for long enough to show up the lesion (two days). Degeneration was found in the cerebral hemispheres, in descending and ascending tracts in the brain-stem, in the cerebellum, and around the margin of the pons and medulla. The changes were best seen in Marchi preparations and showed the histological characteristics of secondary degeneration. It was pointed out, however, that the cellular reaction was considerably slower than that in secondary degeneration after section of the spinal cord or decortication.

Jakob's experimental findings are very similar to ours in human material. He considered that primary traumatic damage, which could be either reversible or lead to necrosis of the nerve fibres, was the basis for his findings and that circulatory disturbances did not play a part.

Careful long-term experiments were carried out by Windle, Groat, and Fox (1944) and by Groat and Simmons (1950) on guinea-pigs. These authors reported changes in nerve cell bodies but did not find significant abnormalities in the nerve fibres. They did not use the Marchi technique, however, without which slight damage would be very difficult to see.

Amongst workers interested in the physical aspects of the problem of head injury, Gama (1835) was probably the first to make use of brain models for experiments. He filled glass flasks with jelly in which he embedded black threads. When a flask was struck he observed a to-and-fro movement of the threads. Gama concluded that concussion was due to vibration ('́branlement) of the brain. These ideas were attacked first by Alquié (1865) and later by Fischer (1871). Both these workers repeated and extended Gama's experiments but failed to confirm his observations. If there is all this vibration, Fischer asked, why is there no tearing of the nerve fibres? But he never investigated this point. Both Fischer and Alquié thought that there was mass movement of the brain away from the point of impact, though Fischer did not think that concussion was due to this but to sudden anaemia of the brain.

In an attempt to prove that concussion was due to a sudden increase in intracranial hydrostatic pressure, Ferrari (1882) experimented with skulls filled with brain tissue or gelatin, in which he implanted microscope cover slips or glass capillary tubes. He then allowed a heavy iron ball to fall from various heights on to the skull which was firmly held or tied down. In many experiments the skull was shattered, but even when it was not, the cover slips, but not the capillary tubes, broke as long as they were implanted not more than $0.5 \mathrm{~cm}$. away from the skull. In these experiments the mechanism is analogous to that in "compression concussion" (Denny-Brown and Russell, 1941), whereas our cases suffered from " acceleration concussion" since the head was almost certainly free to move after the blow.

The work of Holbourn $(1943,1945)$, who approached the subject from a physicist's point of view, has already been mentioned. He considered that of all the forces acting on the head during a blow, rotational acceleration forces and the accompanying shear strains would be the most injurious to a body with the physical properties of brain, that is one that is very incompressible but easily distorted. He constructed a gelatin brain 
model which he subjected to rotation in a circular polariscope, thus rendering the shear strains visible. He thought that these forces would be sufficient to disrupt nerve fibres, blood vessels, synapses, and so on. Since the brain is enclosed in a rigid skull, the only way it can react to forces which tend to distort it is by gliding and swirling movements.

Pudenz and Shelden (1946) recorded the movement of the brain during a blow to the head by highspeed cinematography, using monkeys whose skull caps had been replaced by transparent material. They found gliding and swirling movements of the brain even after subconcussive blows if the head was free to move. When the head was fixed, movements of the brain were much reduced or absent.

White matter lesions in human cases of head injury have only occasionally been described. In 1899 Rosenblath reported the case of a 16-year-old tight-rope walker who fell and was immediately rendered unconscious. Most of the time he lay motionless in what is described as a sleep-like state. He had attacks of decerebration and became very spastic, with one arm extended, the other flexed. He required full nursing care including tube feeding and died eight months after the accident. At necropsy there were no fractures of the skull. The brain weighed only $930 \mathrm{~g}$; t there was ventricular dilatation. There was an immense loss of nerve fibres throughout the cerebral hemispheres and there were a few small softenings, including one in the corpus callosum and one in the superior cerebellar peduncle. Degeneration could be traced into the cortex (in this respect the case differs from ours) but there was no cell loss. There was degeneration in the occipital radiation, in the descending tracts, in the lateral and medial lemniṣci from the middle of the pons upwards, and in the white matter of the cerebellum. The resemblance to our cases is very striking. Rosenblath considered that the nerve fibre loss was due to the effect of the concussion itself on the fibres.

In 1904 Meyer reported the case of a boy whose gun exploded, injuring the left frontal lobe. The patient was soon so well that no neurological examination was made, but he died unexpectedly four weeks after the injury and at necropsy pus was found in the ventricles of the brain. Marchi preparations of the brain showed that apart from degeneration due to the destruction of the frontal lobe there was slight but unmistakable degeneration in the internal capsule, even in the posterior limb, in the external capsule, in the pyramids, in the medial and lateral lemnisci, and a superior cerebellar peduncle. Meyer concluded that the effects of the concussion had been very widespread in this case.
Both Russell (1932) and Greenfield (1938) dis cussed and stressed the probable importance iq concussion of interruption of function of nervह fibres and their sheaths by mechanical damage. $\stackrel{\text { ? }}{\subseteq}$

In their studies on nerve fibres in head injurs Rand and Courville (1934) found retraction bulbe in the neighbourhood of haemorrhages and unde neath cortical contusions. They also mention the retraction bulbs are occasionally seen in areas remote from any focal lesion.

Evans and Scheinker have been interested in the white matter in head injuries and in 1944 reported several cases with lesions from a few days to man years old, in which there was marked fibrous glios and sometimes demyelination of the centruri semiovale with a normal cerebral cortex. This the thought was due to prolonged hypoxia and oedema of the brain due to circulatory disturbances following the injury.

\section{CONCLUSION}

It has been shown that a closed, apparent uncomplicated head injury may be followed by a diffuse degeneration of the white matter an\& consequently may completely and permanently incapacitate the patient. The extreme dementios produced by such a lesion should not be confugeg with coma, which has different physical signs. The nerve fibre degeneration is not due to cortical eep loss, nor to infarction or laceration of brain sos stance. Its pathogenesis has not been determinecl but evidence points to physical damage of nक्ते fibres at the time of injury as a likely cause.

It is at present not possible to say how frequently such white matter degeneration occurs because has not been looked for in acute head injuries. our series of 26 patients dying from head injurio six weeks or more after the accident, it was the significant pathological finding in about one-thira of the cases.

It is impossible to say whether the nerve fibre damage is at any time reversible and what part, any, it plays in the production of the signs of concussion, but the possibility that it may play part should be borne in mind.

It should be remembered that such a diffuse white matter lesion may have to be looked for with care. and that it is not enough to examine the brain-ster reticular formation or the cerebral cortex whe investigating cases of severe disturbance of corg sciousness after head injury.

I am grateful to Dr. P. M. Daniel for his invaluabe: advice, criticism, and enthusiasm at all stages of the worf I am indebted to Dr. P. Glees for sections of the basat ganglia of Case 2. My thanks are due to Dr. M. M. L Prichard and Mr. E. L. Tugwell for the photograph 
and to Mr. R. Beesley and Miss E. Stanley for technical assistance. I am grateful to Mr. W. S. Lewin for permission to use the clinical notes of the patients under his care. This work was done while in receipt of a personal grant from the Medical Research Council.

\section{REFERENCES}

Alquié, A. (1865). Gaz. méd. Paris, 3 ser., 20, 226.

Bright, R. (1831). Reports of Medical Cases, vol. 2, pt. 2, p. 681 . Longman, Rees, Orme, Brown, and Green, London.

man, Rees, Orma, Brown, and Green, London.
Courville, C. B. (1953a). Commotio Cerebri. San Lucas Press, Los Angeles.

(1953b). Contributions to the Study of Cerebral Anoxia. San Lucas Press, Los Angeles.

Denny-Brown, D., and Russell, W. R. (1941). Brain, 64, 93.

Evans, J. P., and Scheinker, I. M. (1944). J. Neurosurg., 1, 306.

(1945). Res. Publ. Ass. nerv. ment. Dis. 24, 254.

Ferrari, A. (1882). Spallanzani (Modena) 2nd ser. 11, 169.

Fischer, H. (1871). In Sammlung klinischer Vorträge, ed. R. Volk mann. Chirurgie, 1, No. 8, p. 119. Breitkopf and Härtel, Leipzig.

Gama, J.-P. (1835). Traité des Plaies de Tête et de l'Encéphalite, Crochard, Paris.

Glees, P. (1943). Brain, 66, 229

Greenfield J. G (1938), Proc roy. Soc. Med., 32, 43.

Greenfin, 62, 129.

Grinker, R. R. (1925). Z. ges. Neurol. Psychiat., 98, 433

Groat, R. A., and Simmons, J. Q. (1950). J. Neuropath., 9, 150

Helfand, M. (1939). J. nerv. ment. Dis., 90, 157.

Heymans, C. (1950). Physiol. Rev., 30, 375 .

Hoff, E. C., Grenell, R. G., and Fulton, J. F. (1945). Medicine (Baltimore), 24, 161.
Holbourn, A. H. S. (1943). Lancet, 2, 438.

Hurst, E. W. (1942). Aust. J. exp. Biol. med. Sci., 20, 297.

Jakob, A. (1913). In Histologische und histopathologische Arbeiten, über die Grosshirnrinde, Vol. 5, p. 182. Ed. Nissl, F., and Alzheimer, A. Fischer, Jena.

Lassek, A. M. (1950). Brain, 73, 95

Lindenberg, R. (1955). J. Neuropath., 14, 223

Lumsden, C. E. (1950). Journal of Neurology, Neurosurgery and Psychiatry, 13, 1 .

Malamud, N., and Haymaker, W. (1947). J. Neuropath., 6, 217.

Marburg, O.'(1936). In Handbuch der Neurologie, ed. Bumke, O., and Foerster, O., vol. 11, 1. Springer, Berlin.

Meyer, A. (1904). Amer. J. Insan., 60, 373.

Meyer, A. (1928a). Z. ges. Neurol. Psychiat., 112, 172

Meyer, A. (1928a). Z. ges. Neuro

O'Brien, J. D., and Steegmann, A. T. (1938). Ann. Surg., 107, 486

Pudenz, R. H., and Shelden, C. H. (1946). J. Neurosurg., 3, 487.

Rand, C. W., and Courville, C. B. (1934). Arch. Neurol. Psychiat. (Chicago) 31, 527.

Ricker, G. (1919). Virchows Arch. path. Anat., 226, 180.

Rosenblath, W. (1899). Dtsch. Arch. klin. Med., 64, 406.

Russell, W. R. (1932). Brain, 55, 549.

Schmaus, H. (1890). Virchows Arch. path. Anat., 122, 326, 470.

Schmaus, H. (1890). Virchows Arch. path.

Scholz, W. (1949). Arch. Psychiat. Nervenkr., 181, 621.

Smith, M. C. (1956). Journal of Neurology, Neurosurgery and Psychiatry, 19, 67

- Strich, S. J., and Sharp, P. (1956). Ibid., 19, 62.

Spielmeyer, W. (1925). Z. ges. Neurol. Psychiat., 99, 756

Strecker, E. A., Taft, A. E., and Willey, G. F. (1927). Arch. Neurol. Psychiat. (Chicago), 17, 552.

Windle, W. F., Groat, R. A., and Fox, C. A. (1944). Surg. Gynec. Obstet., 79, 561 .

Witkowski, L. (1877). Virchows Arch. path Anat., 69. 498.

Woolf, A. L. (1954). J. Path. Bact., 67, 1. 